\title{
Splenic Damage during SIV Infection
}

\section{Role of T-Cell Depletion and Macrophage Polarization and Infection}

\author{
Dionna W. Williams, ${ }^{*}$ Elizabeth L. Engle, ${ }^{*}$ Erin N. Shirk, ${ }^{*}$ Suzanne E. Queen, ${ }^{*}$ Lucio Gama, ${ }^{*}$ Joseph L. Mankowski, ${ }^{* \dagger *}$ \\ M. Christine Zink, ${ }^{* \dagger}$ and Janice E. Clements ${ }^{\star \dagger}$
}

From the Departments of Molecular and Comparative Pathobiology, ${ }^{*}$ Pathology,${ }^{\dagger}$ and Neurology, ${ }^{\ddagger}$ Johns Hopkins University School of Medicine, Baltimore, Maryland

\author{
Accepted for publication \\ March 25, 2016. \\ Address correspondence to \\ Janice E. Clements, Ph.D., \\ Department of Molecular and \\ Comparative Pathobiology, \\ Johns Hopkins University \\ School of Medicine, $733 \mathrm{~N}$ \\ Broadway, MRB 831, Balti- \\ more, MD 21205. E-mail: \\ jclements@jhmi.edu.
}

\begin{abstract}
The effects of HIV infection on spleen and its cellular subsets have not been fully characterized, particularly for macrophages in which diverse populations exist. We used an accelerated SIV-infected macaque model to examine longitudinal effects on T-cell and macrophage populations and their susceptibilities to infection. Substantial lymphoid depletion occurred, characterized by follicular burn out and a loss of CD3 T lymphocytes, which was associated with cellular activation and transient dysregulations in CD4/CD8 ratios and memory effector populations. In contrast, the loss of CD68 and $\mathrm{CD} 63^{+} \mathrm{CD}^{+} 8^{+}$macrophages and increase in CD163 cells was irreversible, which began during acute infection and persisted until terminal disease. Mac387 macrophages and monocytes were transiently recruited into spleen, but were not sufficient to mitigate the changes in macrophage subsets. Type I interferon, M2 polarizing genes, and chemokine-chemokine receptor signaling were up-regulated in spleen and drove macrophage alterations. SIV-infected T cells were numerous within the white pulp during acute infection, but were rarely observed thereafter. CD68, CD163, and Mac387 macrophages were highly infected, which primarily occurred in the red pulp independent of T cells. Few macrophages underwent apoptosis, indicating that they are a long-lasting target for HIV/SIV. Our results identify macrophages as an important contributor to HIV/SIV infection in spleen and in promoting morphologic changes through the loss of specific macrophage subsets that mediate splenic organization. (Am J Pathol 2016, 186: 2068-2087; http://dx.doi.org/10.1016/j.ajpath.2016.03.019)
\end{abstract}

The functions, organization, and cellular constituents of the spleen drastically change during HIV infection, as it is infected early during primary disease. ${ }^{1}$ Substantial morphologic changes occur as a result of the persistent infection, including white pulp depletion, perivascular hyalinization, necrosis, extramedullary hematopoiesis, and inflammatory cell infiltrates. ${ }^{2}$ Although not as extensively characterized as other lymphoid organs, the spleen represents an anatomical viral reservoir ${ }^{3-5}$ that occurs, in part, because of the limited penetration of some antiretroviral drugs to the organ. ${ }^{6}$ The spleen also contains potential T-cell and macrophage cellular reservoirs. ${ }^{7} \mathrm{HIV}$-induced splenic $\mathrm{T}$ lymphocyte dysfunction is well characterized and consists of a significant decline in the numbers of CD4 cells, the recruitment of virus-specific cytotoxic $\mathrm{T}$ lymphocytes, and the presence of latently infected memory cells. ${ }^{8-17}$ Macrophages are also important during infection and promote HIV persistence and damage to the spleen. ${ }^{5,18}$ In addition to producing infectious virus, macrophages may also enter into a latently infected state and contribute to viral reservoirs. $^{7,19-29}$ Furthermore, macrophages are immune to the cytopathic effects of HIV infection. ${ }^{5,30-33}$ This suggests that once infected, even if present in a latent state or infected at low levels, these long-lived cells have the potential to

Supported by NIH grants P40 OD013117, P01MH070306, NS077869, NS076357, U19-0AI076113, and R56-AI118753 (J.E.C.).

Disclosures: None declared. 
reactivate virus, produce low-level replication, and present infectious virus to $\mathrm{T}$ cells over the course of many years. ${ }^{34-39}$ Peripheral blood monocytes may also contribute to splenic macrophage populations during HIV infection and promote virus-induced damage, as they can accumulate in the spleens of infected individuals. ${ }^{23}$

Diverse macrophage subsets reside within the red and white pulp compartments of the spleen, and fulfill different functions as a result of their localization. ${ }^{40}$ The four major splenic macrophage populations include tingible body, metallophilic, marginal zone, and red pulp macrophages. Marginal zone and metallophilic macrophages reside in the marginal zone and are critical for eliciting antimicrobial functions by clearance of blood-borne bacteria and viruses. $^{41}$ Follicular tingible body macrophages remove apoptotic B cells during germinal center reactions and are essential for the generation of antigen-specific, high-affinity plasma and memory cells. ${ }^{42}$ Follicular macrophages are also important for presenting antigen to $\mathrm{T}$ cells and initiating the adaptive immune response to pathogens. ${ }^{43}$ Finally, red pulp macrophages are laid down embryonically and mediate erythrocyte phagocytosis, hemoglobin/haptoglobin scavenging, iron recycling, and storage. Splenic macrophages are characterized by their unique functions, distinct localizations, and expression of differential cell markers. ${ }^{41}$

In addition to their unique markers, macrophages also express CD163 and CD68, less specific, general markers that can be used to collectively identify both resident and newly entered splenic cells. ${ }^{41}$ CD163, a glycoprotein member of the scavenger receptor cysteine-rich group B family, and CD68, a low-density lipoprotein binding glycoprotein, are restricted to cells of the monocyte/ macrophage lineage. ${ }^{44-46}$ CD163, a hemoglobin/haptoglobin scavenger receptor, is associated with the resolution of inflammation and is highly expressed on alternatively activated M2-polarized macrophages. ${ }^{47,48}$ In contrast, CD68 is a widely used immunohistochemical marker present on many resident tissue macrophages, and is considered a pan-macrophage marker. ${ }^{49}$ Mac387, an antibody that has specificity for the L1 antigen, may also be used to identify splenic macrophages, and is indicative of a blood monocyte-derived subset. ${ }^{50}$ These newly infiltrated macrophages have a distinct morphology from resident macrophages and also have different functional capacities. ${ }^{51,52}$ The resident and recently infiltrated macrophage subsets may have differing levels of HIV infectivity, and may also promote distinct antiviral and/or inflammatory responses within the spleen. However, the effects of HIV on these different splenic macrophage subsets are not completely understood. It is important to characterize more extensively the diverse macrophage subsets as these cells are long-lived, are highly susceptible to infection, and play critical roles in maintaining splenic function.

Herein, we used an accelerated, consistent SIV-infected pigtail macaque model to examine the longitudinal effects of SIV infection on the spleen. We examined splenic CD163,
CD68, and Mac387 macrophage phenotypes and differential SIV infection of these cells from acute to late stage disease. We found that in addition to morphologic and $\mathrm{T}$ cell alterations, there were profound and long-lasting changes in macrophage populations within the spleen. SIV infection promoted a global increase in CD163 macrophages, and a simultaneous decrease in CD68 cells, that occurred only partially because of apoptosis of these cells. In addition, there was a substantial depletion of fetal-derived red pulp $\mathrm{CD}_{163}{ }^{+} \mathrm{CD} 8^{+}$macrophages, which may compromise splenic iron scavenging. Gene expression profiling demonstrated that the pronounced increase of interferon mediators, M2 polarizing factors, and chemokine-chemokine receptor signaling promoted the regulation of macrophage subsets. All macrophage populations characterized contained SIV RNA, as determined by in situ hybridization analyses, although the subsets had differential patterns and levels of infectivity.

\section{Materials and Methods}

\section{Animals and Ethics Statement}

All animal studies were approved by the Johns Hopkins University Institutional Animal Care and Use Committee and performed according to the guidelines of the US Department of Agriculture Animal Welfare Act and the NIH Guide for the Care and Use of Laboratory Animals. ${ }^{53}$ Sixty pigtailed macaques were involved in the study, 53 of which were i.v. dual inoculated with SIV/DeltaB670 (50, 50\% animal infectious doses) and SIV/17E-Fr (10,000 50\% animal infectious doses) as previously described. ${ }^{54,55} \mathrm{Ma}-$ caques were euthanized at 4 (eight animals), 7 (six animals), 10 (six animals), 14 (five animals), 21 (five animals), 56 (nine animals), and 84 (14 animals) days post infection (dpi), in accordance with federal guidelines and institutional policies. Seven animals were mock infected and served as uninfected controls. Macaques were perfused with sterile saline at euthanasia to remove blood from the vasculature and tissues.

\section{Sample Preparation}

Blood samples were collected at multiple time points before inoculation, and at 4, 7, 10, 14, 21, 56, and 84 dpi. Blood was collected into acid citrate dextrose (Sigma-Aldrich, St. Louis, MO) and a portion used for whole blood immunostaining and flow cytometric analyses. Plasma was separated from the remainder of the blood by centrifugation for the determination of plasma viral load. ${ }^{56-60}$ At euthanasia and concurrent with blood sampling, spleens were harvested, weighed, and sectioned to provide intact tissue for viral load determination, NanoString analyses, immunohistochemistry, and immunohistochemistry with in situ hybridization. Repeated sampling was not performed for these analyses, as spleen samples were isolated from independent animals euthanized at each time point after inoculation. Therefore, 
all splenic observations constitute a cross-sectional study. For example, data points at days 4 and 7 are not directly related, but instead represent samples obtained from different populations of animals infected with SIV for 4 and 7 days, respectively. Repeated sampling was performed for blood analyses, however, and these data were therefore examined longitudinally.

\section{Quantitation of Viral Load in Plasma and Viral RNA in} Tissue

Plasma viral load was determined throughout infection, as well as at the terminal time point. RNA was isolated from $140 \mu \mathrm{L}$ of plasma using the QIAamp Viral RNA Mini kit (Qiagen, Valencia, CA) in accordance with the manufacturer's protocol with the modification of on column DNase digestion (RNase free DNase kit; Qiagen) using RQ1 RNase free DNase (Promega, Madison, WI) in the enzyme mix. Spleen viral RNA was measured at the terminal time point using $25 \mathrm{mg}$ of spleen homogenized using RNA Stat-60 (AMSBio, Cambridge, MA) and RNA isolated using the RNeasy PLUS Mini Kit according to the manufacturer's protocol with the modification of on column DNase digestion (RNase free DNase kit; Qiagen) using TURBO DNase (Life Technologies, Grand Island, NY) in the enzyme mix. Quantification of SIV RNA (for plasma viral load and spleen RNA levels) was performed by RT-PCR using the following primers and probes: forward primer (SGAG21) 5'-GTCTGCGTCATCTGGTGCATTC-3'; reverse primer (SGAG22) 5'-CACTAGGTGTCTCTGCACTATCTGTTTTG-3', probe (pSGAG23) 5'-(FAM)CTTCCTCAGTGTGTTTCACTTTCTCTTCTG-(BHQ_1)-3', as previously described. ${ }^{54}$ Viral loads were log-transformed for statistical analyses.

\section{Immunostaining and Flow Cytometry of PBMC and Spleen Single-Cell Suspensions}

Whole blood samples were stained with fluorochromecoupled CD3, CD4, CD8, HLA-DR, and CD14 antibodies for 20 minutes at room temperature and fixed for 10 minutes with BD FACS Lysing Solution (Becton Dickinson, Franklin Lakes, NJ). Panels with information for all antibodies are listed in Table 1. Cells were immunostained and assayed for flow cytometry immediately following initial isolation, or were cryopreserved in $90 \%$ fetal bovine serum with $10 \%$ dimethyl sulfoxide and stored at $-140^{\circ} \mathrm{C}$ until further analysis. This cryopreservation method is well established and does not result in loss of cell surface markers. ${ }^{61}$ Spleen cells were isolated for flow cytometric analyses by mechanical agitation and teasing from $10 \mathrm{~g}$ of tissue in RPMI 1640 (Gibco, Gaithersburg, MD) with 10\% fetal bovine serum (Atlanta Biologicals, Norcross, GA) using 18 gauge needles with the thumb-end of a $5 \mathrm{~mL}$ syringe and passing through a $100 \mu \mathrm{m}$ cell strainer. On obtaining single-cell suspensions, red blood cells were lysed
Table 1 List of Antibodies Used for Flow Cytometry Immunostaining

\begin{tabular}{lll}
\hline Antibody & Company & Clone \\
\hline CD3 & BD (Franklin Lakes, NJ) & SP34-2 \\
CD4 & Invitrogen (Carlsbad, CA) & S3.5 \\
CD8 & eBioScience (San Diego, CA) & RPA-T8 \\
CD11b & Biolegend (San Diego, CA) & ICRF44 \\
CD14 & Invitrogen & Tuk4 \\
CD16 & eBioScience & $3 G 8$ \\
CD20 & eBioScience & 2H7 \\
CD28 & BD & CD28.2 \\
CD45 & BD & 2 D1 \\
CD69 & Biolegend & FN50 \\
CD95 & BD & DX2 \\
HLA-DR & Invitrogen & Tu36 \\
\hline
\end{tabular}

with mild treatment of ammonium chloride. Single-cell suspensions derived from spleen were stained with fluorochrome-coupled CD45, CD3, CD4, CD69, CD8, CD28, CD95, CD11b, CD14, CD16, HLA-DR, and CD20 antibodies (Table 1). Cells were stained and fixed as described above and as previously described. ${ }^{62}$

Samples were analyzed using a BD LSRFortessa or FACSCalibur cytometer and Diva software version 6.1.3 (Becton Dickinson). FACS data were analyzed using FlowJo version 9.5.1 (FlowJo, Ashland, OR). All antibodies were tested for specificity by FMO. To enumerate plasma CD4 $\mathrm{T}$ lymphocytes (defined as $\mathrm{CD}^{+} \mathrm{CD}^{+}$cells), the frequency of $\mathrm{CD} 4 \mathrm{~T}$ cells relative to the total peripheral blood CD3 population was multiplied by the whole blood complete blood cell count. To enumerate plasma monocytes (defined as CD14 ${ }^{+} \mathrm{HLA}_{-} \mathrm{DR}^{+}$cells), the frequency of CD14 monocytes in the peripheral blood was multiplied by the whole blood complete blood cell count.

Spleen B lymphocytes were defined as $\mathrm{CD} 45^{+} \mathrm{CD} 20^{+}$ HLA-DR ${ }^{+}$. T lymphocytes were defined as $\mathrm{CD} 45^{+} \mathrm{CD} 3^{+}$, followed by the further division of $\mathrm{CD}^{+}$cells into $\mathrm{CD} 8^{+}$and $\mathrm{CD} 4^{+}$populations. CD4 T-cell subsets were characterized according to CD3 positivity, CD8 negativity, CD69 as a marker of activation, ${ }^{63-65}$ and on the basis of $\mathrm{CD} 28$ and $\mathrm{CD} 95$ expression into naïve $\left(\mathrm{CD} 28^{+} \mathrm{CD} 95^{-}\right)$, central memory $\left(\mathrm{CD} 28^{+} \mathrm{CD} 95^{+}\right)$, and effector memory $\left(\mathrm{CD} 28^{-} \mathrm{CD} 95^{+}\right)$ subsets. ${ }^{66}$ Spleen monocytes were defined according to light scatter characteristics, CD11b positivity, CD14 ${ }^{\text {high }}$, CD45 ${ }^{\text {high }}$, and HLA-DR expression. Monocytes were characterized further to determine the frequency of cells with surface CD16. Gating strategies for identification of splenic T lymphocytes and monocytes are illustrated in Supplemental Figure S1.

\section{Histopathology of Spleen}

Spleen sections were fixed in Streck tissue fixative (Streck, Omaha, NE) for 7 days and paraffin embedded, and hematoxylin and eosin staining was performed. To determine histological differences in the spleen during longitudinal 
SIV infection, three random fields of each slide were examined by microscope in a blinded manner by a pathologist (M.C.Z.). Lymphoid depletion is characterized by a loss of follicles, a decreased size of the periarteriolar lymphoid sheath, reduced size of the white pulp, the presence of few to no apparent germinal centers, a loss of overall architecture of the marginal and mantle zones, and irregularly shaped follicles. Lymphoid hyperplasia is defined as polymorphous and enlarged follicles, reactive mantle zones, large germinal centers, and the presence of increased numbers of white pulp follicles.

\section{Immunohistochemistry in Spleen}

CD163, CD68, and Mac387 were used to evaluate splenic macrophages. Collectively, these three markers identify the majority of spleen macrophage populations. ${ }^{41,43}$ Immunohistochemistry was performed on Streck-fixed, paraffinembedded spleen sections. Slides were deparaffinized by heating at $60^{\circ} \mathrm{C}$ for 60 minutes and rehydrated in a graded series of ethanol and water. Slides were pretreated with 10 $\mathrm{mmol} / \mathrm{L}$ sodium citrate, $\mathrm{pH}$ 6.0 (JT Baker, Center Valley, PA), before blocking with Fc receptor Block (Innovex Biosciences, Richmond, CA) and Power Block (Biogenex, San Ramon, CA). Primary antibodies to anti-CD163 (1:5000, clone EDHu-1; AbD Serotec, Raleigh, NC), antiCD68 (1:2500, clone KP1; Dako, Carpinteria, CA), and anti-Mac387 (1:5000, clone Mac 387; Dako) were applied for 1 hour, followed by DAB HRP Peroxidase Substrate (Vector Laboratories, Burlingame, CA) for 10 minutes. For double and triple immunohistochemistry staining, the appropriate antibodies were added sequentially for 1 hour, followed by DAB HRP Peroxidase Substrate. In addition, after immunostaining with each antibody, slides were blocked with Mouse on Mouse Blocking Reagent (Vector Laboratories), a peroxidase block $\left(3 \% \mathrm{H}_{2} \mathrm{O}_{2}\right.$ in methanol), and diluted horse serum to minimize nonspecific signal. Appropriate isotype-matched tissue controls were used.

CD163, CD68, and Mac387 macrophages were examined by microscope in a blinded manner by three independent individuals (M.C.Z., J.E.C., and D.W.W.). To quantitate the presence of the macrophage populations in the germinal center, mantle zone, marginal zone, and red pulp, numerical scores of 0 (none), 1 (minimal), 2 (moderate), or 3 (many) were assigned. The scores for all sections were totaled and divided by the total number of fields to give a mean score for the frequency of macrophages. For our semiquantitative analyses, the mean score for each splenic area was set to one and a fold-change relative to uninfected macaques was determined.

\section{NanoString Analysis}

Spleens were harvested from macaques at 4 (six animals), 7 (six animals), 14 (five animals), 21 (five animals), and 56 (nine animals) dpi. Four mock-infected animals served as controls. RNA was isolated as described above, $250 \mathrm{ng}$ sent to the Johns Hopkins Deep Sequencing and Microarray Core, and NanoString analyses performed as previously described. ${ }^{67}$ Briefly, in the NanoString technology, molecular barcodes attached to target-specific probes enable multiplexed measurement of gene expression without the need of reverse transcription or DNA amplification. In this highly sensitive and reproducible system, barcodes for genes of interest are combined with those for negative (genes whose sequences lack specificity and cross-reactivity with mammalian genes) and positive (serially diluted probes that enable quality assurance) controls. In our study, barcodes for 76 genes of interest (including actins, GAPDH, $H P R T$, and $P B G D$ as housekeeping genes) were combined with those for six positive and eight negative controls to generate CodeSets according to the company's guidelines, based on rhesus macaque annotated sequences (NanoString, Seattle, WA). Raw data, which are proportional to gene copy numbers, were normalized by the geometric mean of the four housekeeping genes. The four housekeeping genes were not significantly altered as a result of SIV infection and had comparable copy numbers in both infected and uninfected macaques (data not shown). After normalization, the copy numbers for each target gene were compared to those for the negative controls. Target genes with normalized copy numbers below that of the negative controls were assigned values of 1 . Genes that consistently received values of 1 throughout longitudinal infection were excluded because of low hybridization or probe efficiency. One gene (of 76) met criteria for exclusion. A portion of the animals in this NanoString analyses were included in a recently published study. ${ }^{67}$ Our NanoString analyses were performed on tissue homogenates representative of the whole organ, and it is not possible to ascribe changes in gene expression to any specific cell population.

\section{Combined Immunohistochemistry and in Situ Hybridization}

To examine SIV RNA-positive CD163, CD68, and Mac387 macrophages in the spleen, combined immunohistochemistry and in situ hybridization were performed as previously described. ${ }^{58}$ Briefly, fixed, paraffin-embedded spleen sections were deparaffinized, rehydrated in a graded ethanol series, and pretreated with $25 \mu \mathrm{g} / \mathrm{mL}$ Proteinase K (Roche, Indianapolis, IN). After post-fixing with $4 \%$ paraformaldehyde (SigmaAldrich), in situ hybridization was performed using a SIVmac239 digoxigenin-UTP labeled riboprobe. Immunohistochemistry was then performed for CD163, CD68, or Mac387. Appropriate isotype-matched tissue controls were used. Uninfected and SIV-infected tissues were used as negative and positive controls, respectively.

The number of SIV-RNA CD163, CD68, and Mac387 macrophages was determined by manually counting doublelabeled cells in five random fields of spleen. In addition, the number of small, punctate SIV-RNA positive cells in the 
white pulp that lacked positivity for the macrophage immunohistochemical markers (indicative of T lymphocytes) was determined by manually counting in five follicles.

\section{Cleaved Caspase-3 Immunohistochemistry}

Cleaved caspase-3 analysis was performed using the Leica Bond RX automated immunostainer (Leica Microsystems, Wetzlar, Germany). Cleaved caspase- 3 antibody $(0.252 \mu \mathrm{g} /$ $\mathrm{mL}$, Cell Signaling) was used and immunohistochemistry performed using the Leica Bond Polymer Refine Detection Kit according to manufacturer's protocol. The Leica Bond Polymer Refine Red Detection Kit was used for double staining with cleaved caspase-3 $(0.126 \mu \mathrm{g} / \mathrm{mL}$, Cell Signaling) and CD68 and CD163 antibodies according to manufacturer's protocol.

\section{Statistical Analysis}

Statistical analyses were performed using Prism software version 6.0 (GraphPad Software, Inc., San Diego, CA). The Kruskal-Wallis analysis of variance test was performed to determine significant changes in gene expression during SIV infection as compared to uninfected control animals $(\alpha \leq 0.05)$, followed by Dunn's multiple comparisons test $(P \leq 0.05)$. Linear regression was used to determine correlations between interferon (IFN)- $\beta$ and interferon stimulated genes. The Mann-Whitney test was used to determine statistical significance for all other data $(P \leq 0.05)$.

\section{Results}

\section{Cellular and Architectural Changes Occur in the Spleen during SIV Infection}

The spleen has abundant lymphocytes and macrophages, the two major cellular targets of HIV/SIV infection, which represent potential viral reservoirs and pose major obstacles to HIV eradication. Of these cell types, splenic macrophages have been largely understudied. To provide a more complete understanding of splenic alterations during SIV infection, we used a well-established, consistent, accelerated pigtail macaque model. In this model, the long progression to disease, typical of lentiviral infection, occurs within 84 dpi, and is characterized by acute $(4,7$, and $10 \mathrm{dpi})$, asymptomatic (14 and $21 \mathrm{dpi}$ ), and chronic (56 dpi) stages, after which time terminal disease is achieved at $84 \mathrm{dpi}$ (Figure 1A) ${ }^{54,55}$ During the progression from acute to terminal disease, plasma viremia increased and remained high, and CD4 T lymphocytes declined, which is characteristic of HIV/SIV infection (Figure 1A).

We characterized the Tlymphocyte populations during the course of SIV infection. There was a significant decrease in the percentage of splenic CD4 T lymphocytes during acute infection (7 dpi), with a concomitant increase in the percentage of $\mathrm{CD}^{+}$cells at the same time point, as determined by flow cytometry (Figure 1B). However, the relative frequencies of these T lymphocyte subsets were restored by 21 dpi to levels similar to that of uninfected macaques, and were maintained until terminal disease. Despite the restoration in the relative frequencies of spleen $\mathrm{T}$ lymphocytes, the CD4 cells that remained had alterations in cellular activation and dysregulated memory subsets, as determined by CD69 and CD28/CD95 flow cytometric analyses, respectively. In uninfected macaques, $23.4 \% \pm 1.8 \%$ of CD4 T cells expressed CD69, an early marker of $\mathrm{T}$ cell activation (Figure 1C). During acute infection (7 dpi), expression of CD69 on CD4 T lymphocytes significantly increased to $41.4 \% \pm 3.2 \%$, decreased during asymptomatic infection $(26.0 \% \pm 6.6 \%)$, but later increased again during chronic infection at every time point examined, relative to uninfected animals (Figure 1C). In addition to cellular activation, there were also changes in the memory populations of CD4 T cells. In uninfected animals, central memory cells comprised the majority of spleen CD4 T lymphocytes, and naïve cells represented the second most populous subset (Figure 1D). There was also a minor population of effector memory cells in uninfected animals. During acute infection (7 dpi), there was a significant increase in the effector memory subset, a decrease in central memory cells, and an almost complete loss of naïve CD4 T cells (Figure 1D). These naïve cells were restored during the asymptomatic phase at $21 \mathrm{dpi}$, suggesting that additional CD4 $\mathrm{T}$ cells were recruited into the spleen from the peripheral blood. During chronic and terminal disease, the memory subsets more closely resembled the frequencies of lymphocytes found in uninfected animals, where central memory cells comprised the major CD4 cell subpopulation (Figure 1D).

Pathologic changes in the spleens of SIV-infected and uninfected animals were examined by histochemical staining. A pathologist examined the hematoxylin and eosinstained slides for lymphoid depletion, as characterized by a loss of follicles and decreased size of the periarteriolar lymphoid sheath, and lymphoid hyperplasia, indicated by enlarged and numerous follicles, in a blinded manner. There was substantial lymphoid depletion in SIV-infected macaques in both acute and chronic/terminal disease (Table 2). There was some recovery of lymphocytes during asymptomatic infection, when most of the spleens had a normal appearance with no abnormalities. Representative images of hematoxylin and eosin staining illustrate lymphoid hyperplasia at $4 \mathrm{dpi}$, and lymphoid depletion at 56 and 84 dpi (Figure 1E). The splenic lymphoid depletion that occurred in our animal model is consistent with studies from individuals with HIV/AIDS, particularly to those from the pre-antiretroviral therapy era. ${ }^{2,9,10}$

\section{Spleen Macrophages Undergo Dynamic Changes in Cellular Markers}

Macrophages represent one of the first cell types infected during primary HIV/SIV disease and can continue to harbor 


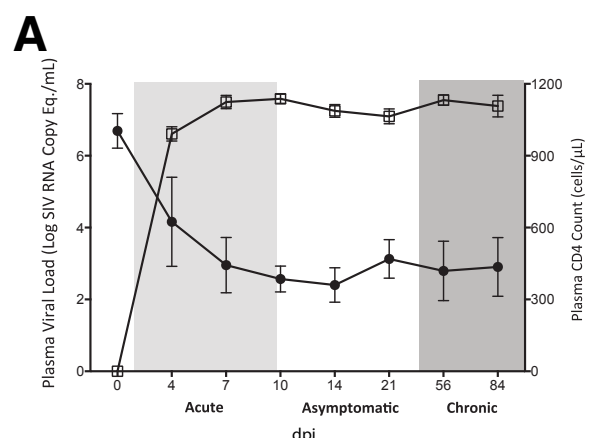

B
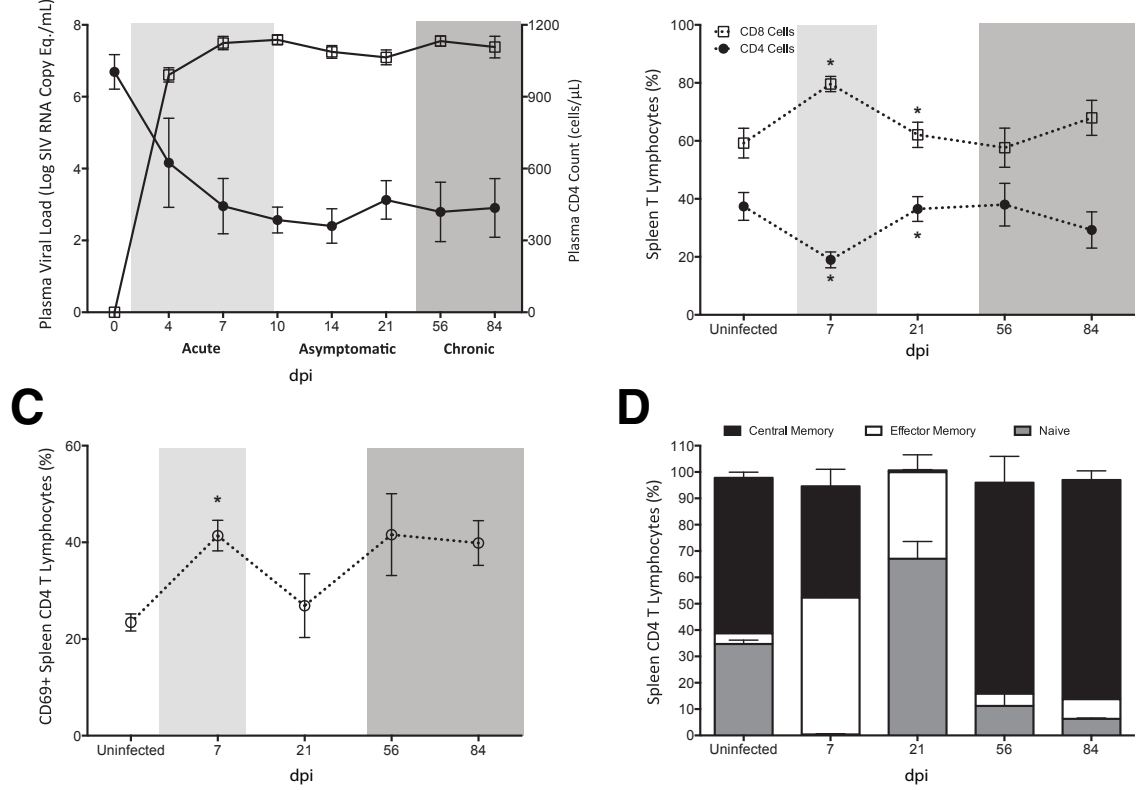

D

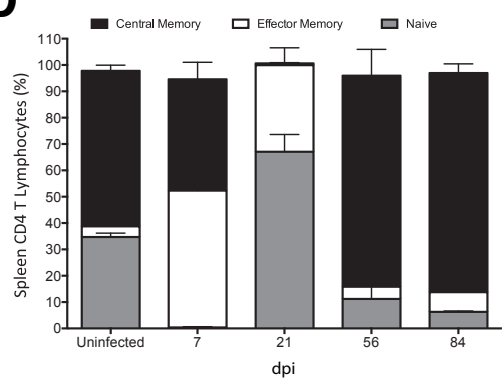

E
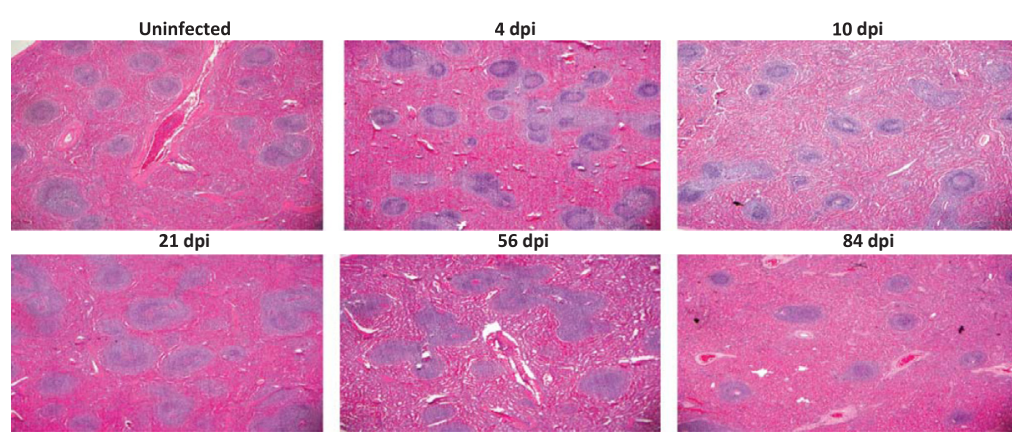

Figure 1 Analysis of spleen T cells and pathology during longitudinal SIV infection. Pigtailed macaques were inoculated with an immunosuppressive swarm and a neurovirulent clone of SIV. A: Peripheral blood was obtained from SIV-infected macaques and RNA isolated at 4, 7, 10, 14, 21, 56, and 84 dpi to determine plasma viral load (open squares) by quantitative RT-PCR. CD4 T lymphocytes (closed circles) were enumerated in whole blood by flow cytometry. The acute (light shading), asymptomatic, and chronic (dark shading) phases of SIV infection are depicted. B-D: Single cell suspensions were obtained from spleen at 7, 21, 56, and $84 \mathrm{dpi}$ and cells analyzed by flow cytometry. B: The frequency of CD8 (open squares) and CD4 T lymphocytes (closed circles) relative to the total spleen CD3 T lymphocyte population was determined by fluorescenceactivated cell sorter analyses. C: The percentage of splenic CD4 T lymphocytes that expressed cell surface CD69 was examined in uninfected animals and at 7 , 21,56 , and $84 \mathrm{dpi}$, as an indicator of cellular activation. D: The frequency of $\mathrm{CD}_{2} 8^{+}$naïve (gray bars), $\mathrm{CD}^{+} 5^{+}$effector memory (white bars), and $\mathrm{CD}_{28}{ }^{+} \mathrm{CD}^{+} 5^{+}$central memory (black bars) CD4 T lymphocytes in the spleen was determined by flow cytometry in uninfected macaques and at 7, 21, 56, and $84 \mathrm{dpi}$. E: Representative hematoxylin and eosin -stained spleen sections from uninfected and SIVinfected macaques euthanized at 4, 10, 21, 56, and $84 \mathrm{dpi}$. Solid lines connecting data points denote cumulative and longitudinal blood sampling of the same animals at every time point after inoculation. Dashed lines connecting data points indicate crosssectional study of independent groups of animals after euthanasia at each time point. Statistical significance was determined by Mann-Whitney test. Data are expressed as means \pm SD. ${ }^{*} P \leq 0.05$ versus the preceding day after inoculation. Original magnification, $\times 2(\mathbf{E})$. Eq, equivalents. infectious virus, even after effective antiretroviral therapy and plasma viral suppression. ${ }^{68-70}$ To evaluate spleen macrophage populations during longitudinal SIV infection, we used three specific macrophage markers: CD163 (a monocyte/macrophage specific haptoglobin/hemoglobin scavenger receptor ${ }^{71}$ ), CD68 (a general macrophage marker and glycoprotein scavenger receptor), and Mac387 (an antibody that detects the $\mathrm{L} 1$ antigen, an intracellular calcium binding protein highly expressed in myelomonocytic cells $^{72}$ ). Collectively, these markers account for the majority of splenic macrophage subsets, including tingible body, marginal zone, metallophilic, and red pulp macrophages. ${ }^{41}$ Each macrophage marker was assessed by immunohistochemistry and analyzed in the germinal center, mantle zone, marginal zone, and red pulp in three random fields, in a blinded manner (M.C.Z., J.E.C., D.W.W.).

We identified four distinct macrophage populations in the spleen of uninfected animals. Macrophages were phenotypically identified by expression of CD68, CD163, or Mac387. CD68 single positive cells primarily resided in the germinal center, and represented tingible body macrophages ${ }^{43}$ (Figure 2, A and C). Although not as prevalent as in the germinal center, CD68 macrophages were also present in the other areas of the spleen. In contrast, CD163 and Mac387 cells were not present in the germinal center and represented only a small population of the macrophages in the red pulp. CD163 and Mac387 macrophages primarily resided in the mantle and marginal zones (Figure 2, A and C). To further

Table 2 Prevalence of Spleen Pathology during SIV Infection

\begin{tabular}{lllll}
\hline Variable & Uninfected & Acute infection & Asymptomatic infection & Chronic infection \\
\hline No pathology & 72 & 22 & 48 & 22 \\
Lymphoid hyperplasia & 14 & 15 & 19 & 21 \\
Lymphoid depletion & 14 & 63 & 33 & 57 \\
\hline
\end{tabular}

Data are given as percentage. 
A

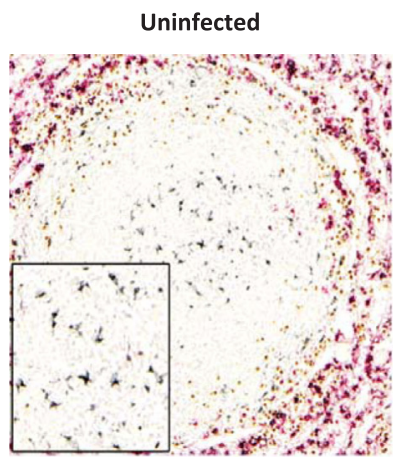

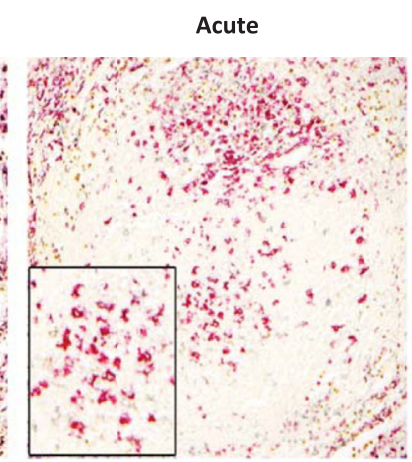
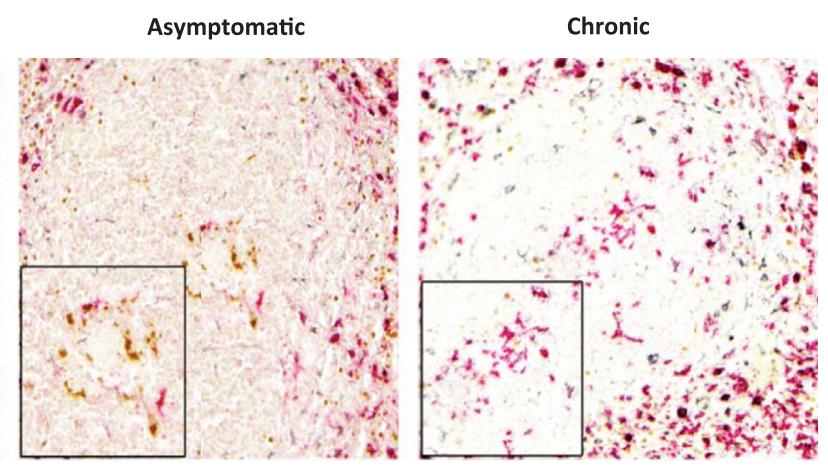

B
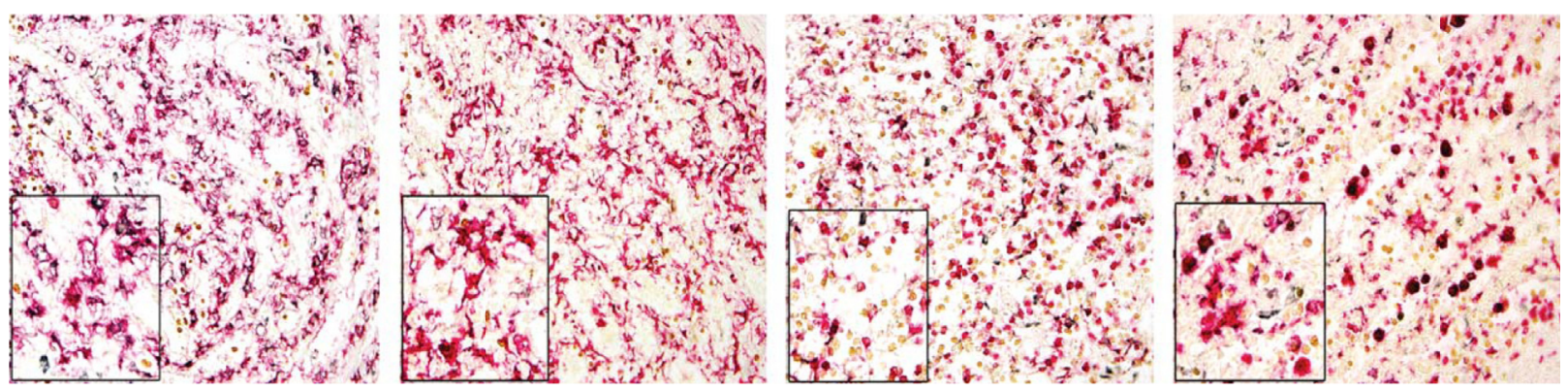

C

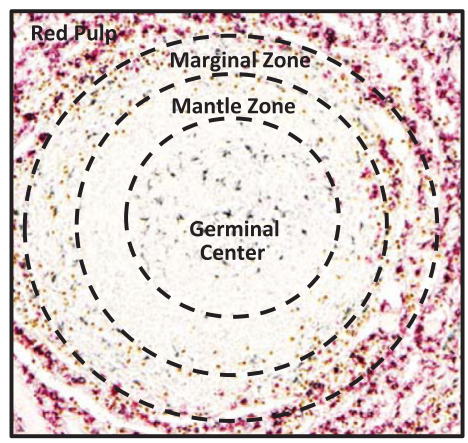

D

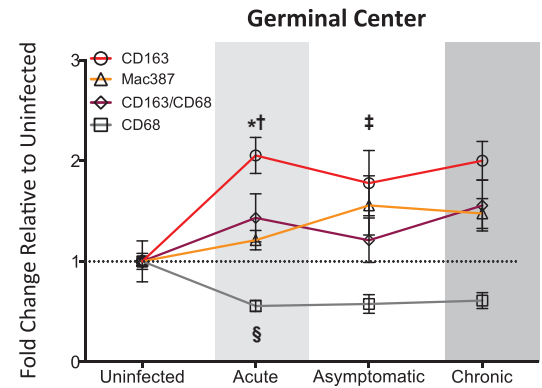

$F$

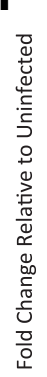

E

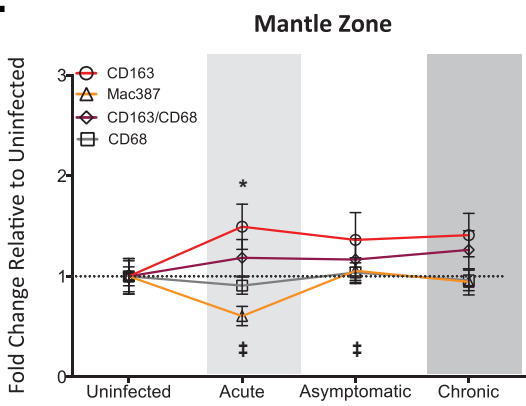

G

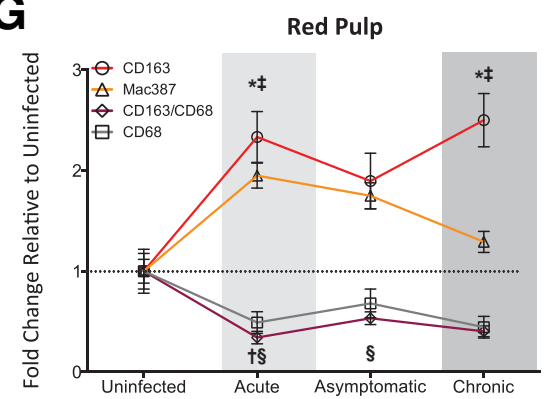

Figure 2 Analysis of spleen macrophage populations. Immunohistochemistry was performed on spleen sections for CD68 (gray), CD163 (red), CD163/CD68 (gray and red), and Mac387 (brown) macrophages in the white (A) and red pulp (B) of uninfected and SIV-infected macaques. Representative images are shown. Boxed insets show higher magnification of macrophages in the white (A) and red pulp (B) of uninfected and SIV-infected animals. C: A representative image of the white pulp in an uninfected macaque demonstrates the germinal center, mantle zone, marginal zone, and red pulp, as indicated by dashed line demarcations. D-G: To quantitate the presence of macrophages in spleen, numerical scores of 0 to 3 were assigned for each marker in the splenic regions and averaged. The fold-change of the mean scores for infected macaques was determined relative to uninfected controls, which was set to 1 . The fold-change for CD68 (gray line with squares), CD163 (red line with circles), CD163/CD68 (purple line with diamonds), and Mac387 (yellow line with triangles) macrophages was determined for the germinal center (D), mantle zone (E), marginal zone (F), and red pulp (G) during the acute, asymptomatic, and chronic phases of infection. The acute (light shading), asymptomatic, and chronic (dark shading) phases of SIV infection are depicted. Cross-sectional study of independent groups of animals after euthanasia at each time point was performed and the data depicted using solid lines connecting data points for better visualization. Statistical significance was determined by Mann-Whitney test. $P \leq 0.05$ versus the preceding day after inoculation for all comparisons. Data are expressed as means \pm SD. ${ }^{*} P<0.05$ CD163 macrophages versus the preceding time point; ${ }^{\dagger} P<0.05$ CD163/CD68 macrophages versus the preceding time point; ${ }^{\ddagger} P<0.05$ Mac387 macrophages versus the preceding time point; and ${ }^{\S} P<0.05$ CD68 versus the preceding time point. Original magnifications: $\times 10(\mathbf{A}) ; \times 20(\mathbf{B}$ and $\mathbf{C})$. 
identify the phenotypes, triple immunostaining was performed for the macrophage markers. Macrophages that expressed both CD163 and CD68 were predominantly localized to the red pulp and comprised the majority of macrophages in this area of the spleen (Figure 2B). $\mathrm{CD}_{163}{ }^{+} \mathrm{CD}_{68}{ }^{+}$macrophages were also present at the proximal region of the marginal zone, directly adjacent to the red pulp. Mac387 cells appeared to be a unique population, as they did not express either of the other two macrophage markers, which is consistent with the work of others. ${ }^{51}$ Data summarizing the macrophage populations present in the uninfected spleen are listed in Table 3.

There were profound and significant changes in all splenic macrophage populations during SIV infection, the majority of which began during acute infection and persisted during terminal disease. First, there was a global decrease in CD68 macrophages, relative to control animals (Figure 2, A and B). The significant loss of CD68 cells $(0.56 \pm 0.06$-fold change, relative to uninfected controls) consistently occurred at every phase of disease, and was most prominent in the germinal center (Figure 2D). A similar decline in CD68 macrophages also occurred in the marginal zone and red pulp (Figure 2, $\mathrm{F}$ and $\mathrm{G})$. Concomitant with the down-regulation of CD68 was a significant increase in CD163 macrophages, as compared to uninfected macaques (Figure 2, D-G). This upregulation in CD163 occurred at every stage of SIV infection, but was particularly striking during the acute phase, where the greatest increase occurred in the germinal center ( $2.33 \pm 0.25$-fold change, relative to uninfected controls) and the red pulp ( $2.50 \pm 0.26$-fold change, relative to uninfected controls) (Figure 2, D and G). There was a significant decrease in red pulp $\mathrm{CD} 163^{+} \mathrm{CD} 68^{+}$macrophages during acute $(0.34 \pm 0.06$-fold change), asymptomatic $(0.53 \pm 0.06$ fold change), and chronic/terminal disease $(0.40 \pm 0.05$-fold change), as compared to controls (Figure $2 \mathrm{G}$ ). The decline of these cells has major implications for splenic function, as they are a fetal-derived macrophage subset that represented the major macrophage red pulp cellular constituent in uninfected macaques $^{73}$ (Figure 2B).

Table 3 Macrophage Populations Present in the Uninfected Spleen

\begin{tabular}{lclll}
\hline Variable & $\begin{array}{l}\text { Germinal } \\
\text { center }\end{array}$ & $\begin{array}{l}\text { Mantle } \\
\text { zone }\end{array}$ & $\begin{array}{l}\text { Marginal } \\
\text { zone }\end{array}$ & Red pulp \\
\hline CD68 & $\mathbf{2 . 3} \pm \mathbf{0 . 2}$ & $\mathbf{1 . 1} \pm \mathbf{0 . 1}$ & $1.8 \pm 0.1$ & $1.3 \pm 0.3$ \\
CD163 & $0 \pm 0$ & $0.1 \pm 0.1$ & $1.3 \pm 0.2$ & $1.0 \pm 0.3$ \\
CD68/CD163 & $0.3 \pm 0.2$ & $0.1 \pm 0.1$ & $\mathbf{2 . 1} \pm \mathbf{0 . 3}$ & $\mathbf{3 . 0} \pm \mathbf{0}$ \\
Mac387 & $0 \pm 0$ & $\mathbf{1 . 0} \pm \mathbf{0 . 2}$ & $\mathbf{2 . 2} \pm \mathbf{0 . 2}$ & $1.4 \pm 0.2$ \\
\hline
\end{tabular}

To quantitate the presence of each macrophage subset in seven uninfected macaques, three random fields were analyzed and numerical scores of $0,1,2$, or 3 were assigned. In this scoring system, 0 represented an absence of the macrophage population, 1 indicated a minimal presence ( $1 \leq 20$ cells), 2 indicated a moderate presence of the macrophages (20 to 100 cells), and 3 indicated the presence of many macrophages in spleen ( $\geq$ 100 cells). Data are expressed as means \pm SD. Bold text indicates the predominant macrophage subset(s) within each area of spleen.
In contrast to the long-lasting decreases of CD68 and $\mathrm{CD} 163^{+} \mathrm{CD}^{+} 8^{+}$macrophages, and the increase in CD163 cells, there was also an increase in Mac387 macrophages that occurred transiently, at distinct phases of disease. This significant increase in Mac387 cells occurred in the germinal center $(1.56 \pm 0.29$-fold change) and marginal zone (1.41 \pm 0.10 -fold change) during asymptomatic disease, as compared to uninfected animals (Figure 2, A, D, and $\mathrm{F}$ ). This was preceded by a significant decrease in Mac387 cells in the mantle zone $(0.60 \pm 0.09$-fold change) during acute infection (Figure 2E), suggesting that these macrophages were recruited from the mantle zone into the other splenic locations. The loss of mantle zone Mac387 macrophages was short-lived, as they returned to baseline levels in the asymptomatic phase of infection (Figure 2E). Similarly, the presence of Mac387 cells in the germinal center and marginal zone also resolved during chronic/ terminal disease. Finally, there was increased cellularity and a loss of higher-order red pulp structure at end-state disease, which began to occur during the asymptomatic stage (Figure 2B). The only other notable change during late stage disease was the presence of $\mathrm{CD} 163^{+} \mathrm{CD} 68^{+}$germinal center macrophages, which were not observed at any other time during infection (Figure 2A).

\section{Type I Interferon and M2 Polarizing Gene Products Are Produced during SIV Infection}

To examine the molecular changes in spleen that accompanied the alterations in splenic lymphocytes and macrophages, we examined global changes in spleen gene expression using NanoString barcoding technology. In this technology, molecular barcodes were attached to targetspecific probes to enable multiplexed measurement of gene expression for 76 genes of interest, four of which were housekeeping genes that were used for normalization. The normalized copy numbers for the uninfected macaques were then set to one, and a fold-change relative to uninfected animals was determined. Forty-three genes were significantly changed during SIV infection, as compared to uninfected macaques. Type I interferon responses were the most abundant class of genes up-regulated in the spleen. IFN- $\beta$ (Figure 3A), MxA (Figure 3B), IRF7 (Figure 3C), STAT2 (Figure 3G), and SOCS3 (Figure 3I) were all significantly increased compared to control animals. IFN- $\alpha$ and IL-12 were also increased during SIV infection, but to a lesser extent than IFN- $\beta$ and the other interferon-stimulated genes (Figure 3, J and K). This may be because of the increase in the anti-inflammatory cytokine IL-10 (Figure 3F), which can inhibit IFN- $\alpha$ production. ${ }^{74}$ In contrast to IFN- $\beta$, type II interferon responses were minimally elicited in spleen, as there was only a small, but significant, increase in IFN- $\gamma$ (Supplemental Figure S2A).

In addition to changes in expression of genes related to interferon signaling, genes involved in macrophage polarization pathways were also altered during SIV infection. 
A

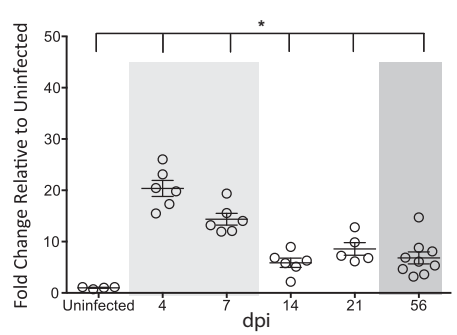

D

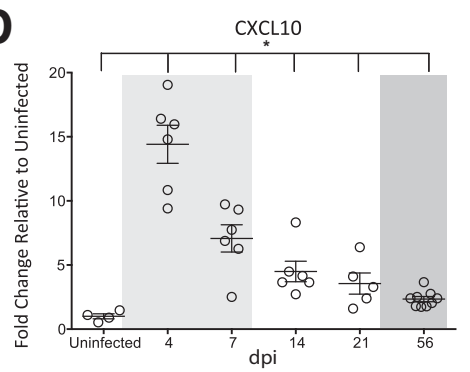

G

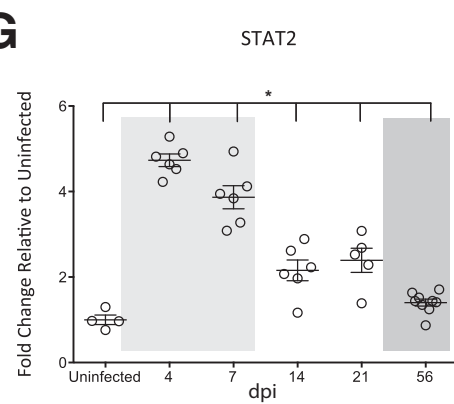

J

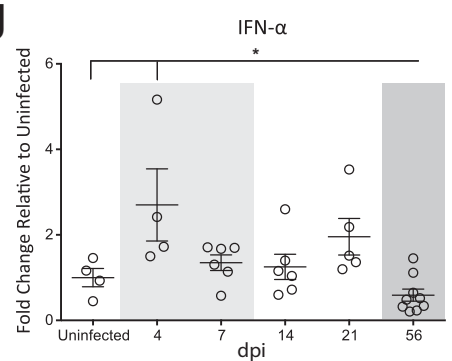

B

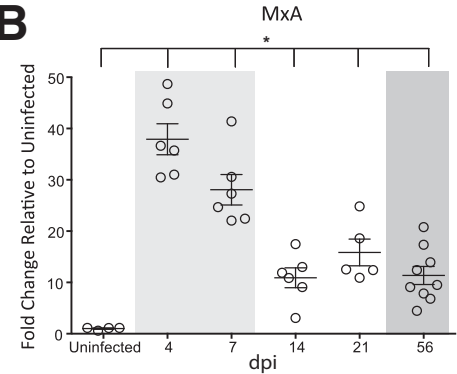

E

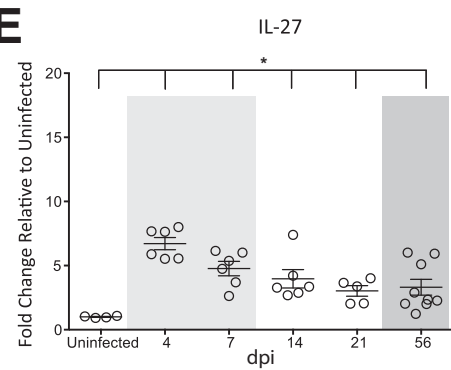

H

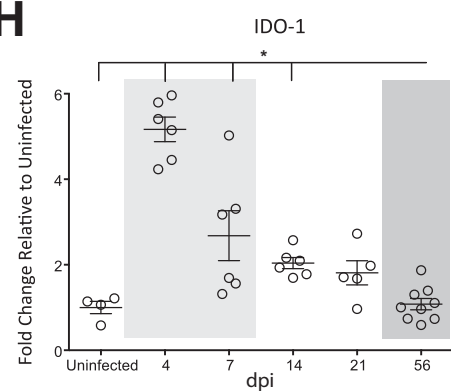

$\mathrm{K}$

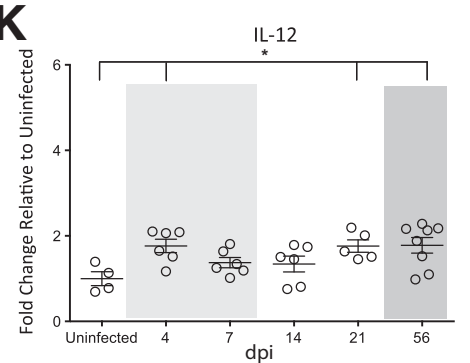

C

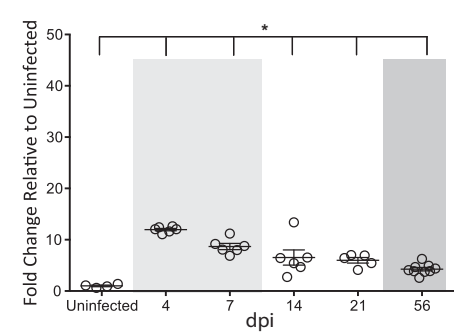

$F$

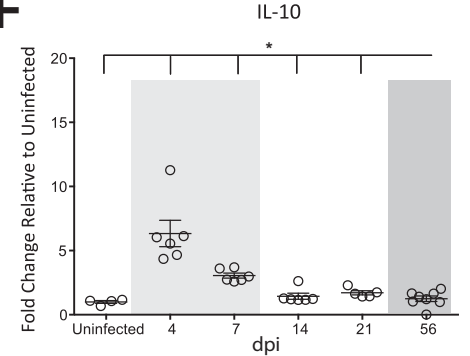

I

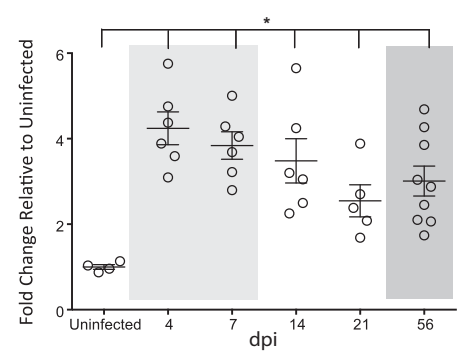

L

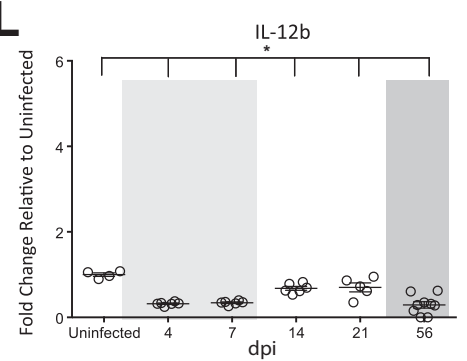

Figure 3 Quantitation of interferon-stimulated genes. RNA was isolated from the spleen in uninfected animals and at 4, 7, 14, 21, and 56 dpi and gene expression analyses performed by NanoString barcoding technology. The relative counts of each gene product were determined on normalizing to four housekeeping genes. The fold-change of each gene was determined relative to uninfected controls, which was set to 1 . The longitudinal fold-changes in interferon (IFN)- $\beta$ (A), MxA (B), IRF7 (C), CXCL10 (D), IL-27 (E), IL-10 (F), STAT2 (G), ID0-1 (H), SOCS3 (I), IFN- $\alpha$ (J), IL-12 (K), and IL-12b (L) in the spleen. The acute (light shading), asymptomatic, and chronic (dark shading) phases of SIV infection are depicted. Statistical significance was determined by KruskalWallis analysis of variance test followed by Dunn's multiple comparison analysis. Vertical lines indicate a significant difference between the indicated dpi and uninfected animals, as determined by the Dunn's multiple comparison analysis. Data are expressed as means \pm SD. ${ }^{*} P \leq 0.05$ for infected animals at all time points relative to uninfected macaques.

CXCL10 (alias IP-10) (Figure 3D), IL-27 (Figure 3E), and IDO-1 (Figure 3H) were significantly increased in infected macaques. These factors, as well as IL-10, promote M2 macrophage polarization ${ }^{74-76}$ and may have contributed to the increase in CD163 macrophages in the spleen (Figure 2). In agreement with a skewing toward M2 polarization, there was a significant decrease in the M1 polarizing cytokine IL$12 \mathrm{~b}$ in SIV-infected animals ${ }^{77,78}$ (Figure 3L). In addition, cytokines produced by M1-polarized macrophages were not elicited in spleen, including IL- $1 \beta$, TNF- $\alpha$, and IL- 6 , further indicating a shifting toward an M2 macrophage phenotype (Supplemental Figure S2, B-D).

IFN- $\beta$ may directly contribute to a skewing toward M2 macrophage polarization, as it was significantly positively correlated with CXCL10 $\left(R^{2}=0.6985, P<0.0001\right)$, IL-27 $\left(R^{2}=0.5832, P<0.0001\right), \quad \mathrm{IL}-10 \quad\left(R^{2}=0.4670\right.$, $P<0.0001)$, and IDO-1 $\left(R^{2}=0.5989, P<0.0001\right)$, and negatively correlated with IL-12b $\left(R^{2}=0.3716, P=0.002\right)$. In contrast, there was no correlation among the macrophage polarizing factors and IFN- $\alpha$ expression (data not shown). These 
data indicate that an anti-inflammatory immune response is induced in the spleen during SIV infection as a result of an increase in IFN- $\beta$, which promotes M2 macrophage polarization.

\section{Peripheral Blood Monocytes Are Recruited into the Spleen by Monocyte Chemokines and Chemokine Receptors}

To understand the changes in macrophage subsets and polarization, flow cytometry was used to characterize the cellular populations in spleen, particularly monocytes because they contribute to splenic macrophages in the marginal and mantle zones. The frequency of monocytes, as well as T and B lymphocytes, relative to the total number of splenic leukocytes, was determined. There was a significant increase in monocytes in the spleen of SIV-infected macaques, as compared to uninfected animals during acute infection (Figure 4A). There was a further increase during asymptomatic infection, which was maintained throughout chronic/terminal disease. In contrast to the changes in
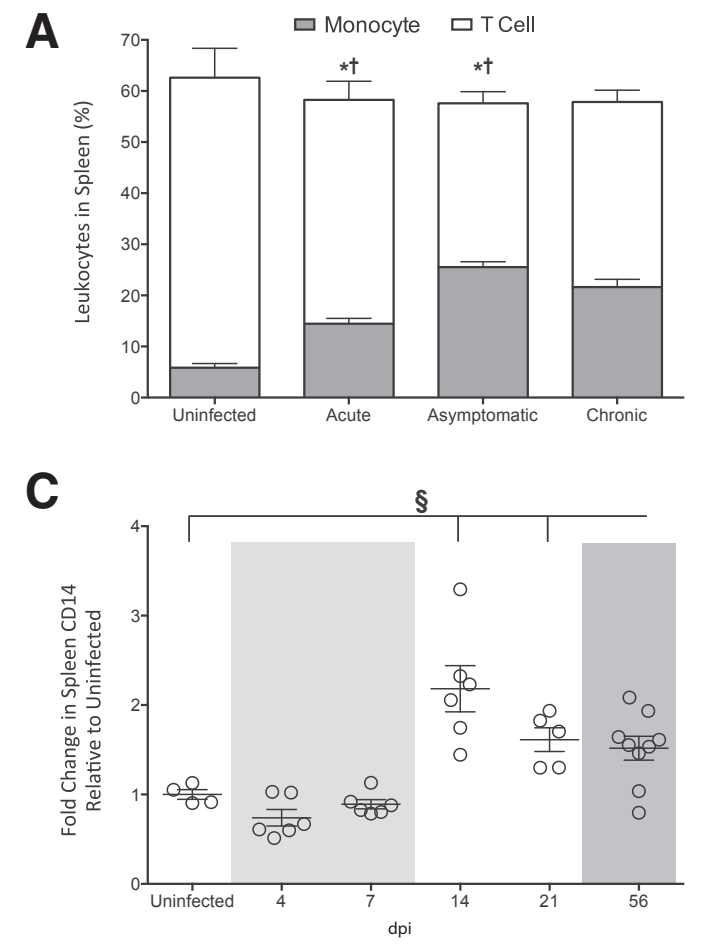

monocytes, the $\mathrm{T}$ lymphocyte population declined during both acute and asymptomatic disease (Figure 4A). There were no significant changes in the frequency of B lymphocytes in the spleen during SIV infection (uninfected macaques, $38.2 \% \pm 3.6 \%$; acute infection, $41.8 \% \pm 3.9 \%$; asymptomatic infection, $43.2 \% \pm 7.2 \%$; chronic infection, $42.3 \% \pm 3.0 \%$ ), suggesting that the alterations in monocyte and $\mathrm{T}$ lymphocyte subsets were specific and did not occur as a result of changes in all splenic leukocytes.

In addition to increasing in number, splenic monocytes underwent changes in cell surface CD16 expression, an activation/maturation marker that is up-regulated upon differentiation of monocytes into tissue macrophages. ${ }^{79,80}$ In uninfected macaques, only $14.1 \% \pm 0.4 \%$ of splenic monocytes expressed CD16 (Figure 4B). This was significantly increased during SIV infection as early as $7 \mathrm{dpi}$, and peaked at 21 dpi where $88.4 \% \pm 2.0 \%$ of cells expressed CD16. To determine whether the increase in spleen monocytes occurred as a result of extravasation from the peripheral blood, we next enumerated blood monocytes in infected and
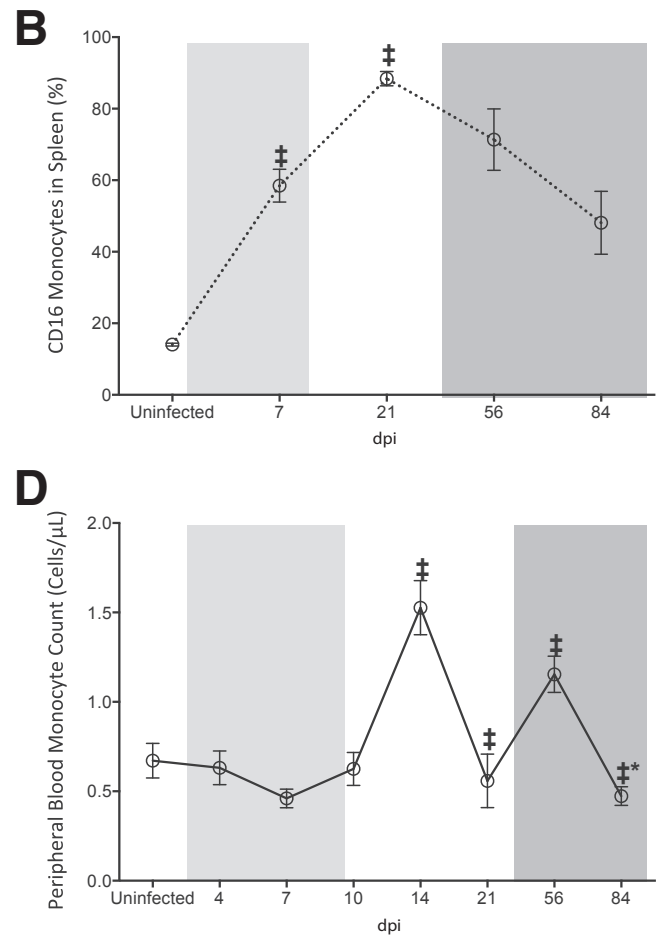

Figure 4 Changes in spleen monocyte cells during SIV infection. A: Single-cell suspensions were generated from spleens isolated from uninfected and SIVinfected macaques during the acute $(4,7$, and $10 \mathrm{dpi}$ ), asymptomatic (14 and $21 \mathrm{dpi})$, and chronic (56 and $84 \mathrm{dpi}$ ) phases of infection. Cell suspensions were analyzed by flow cytometry to determine the frequency of monocytes (gray bars) and T lymphocytes (white bars) in the spleen leukocyte population. B: Spleen cell suspensions were analyzed by flow cytometry to determine the frequency of monocytes that expressed cell surface CD16 in uninfected animals and at 7, 21, 56, and $84 \mathrm{dpi}$. C: RNA was isolated from the spleen from uninfected animals and at 4, 7, 14, 21, and $56 \mathrm{dpi}$ and CD14 gene expression analyses performed by NanoString barcoding technology. The relative count of CD14 was determined on normalizing to four housekeeping genes, and the fold-change in the SIVinfected animals relative to the uninfected controls, which was set to 1, determined. D: Whole blood was collected and immunostained with fluorochromecoupled anti-CD14 to determine the frequency of peripheral blood CD14 monocytes by flow cytometry in uninfected animals and at 4, 7, 10, 14, 21, 56, and $84 \mathrm{dpi}$. The acute (light shading), asymptomatic, and chronic (dark shading) phases of SIV infection are depicted. Solid lines connecting data points denote cumulative and longitudinal blood sampling of the same animals at every time point after inoculation. Dashed lines connecting data points indicate crosssectional study of independent groups of animals after euthanasia at each time point. A, B, and D: Statistical significance was determined by Mann-Whitney test. Statistical significance was determined by Kruskal-Wallis analysis of variance test followed by Dunn's multiple comparison analysis. C: Vertical lines indicate a significant difference between the indicated dpi and uninfected animals, as determined by the Dunn's multiple comparison analysis. Data are expressed as means \pm SD. ${ }^{*} P \leq 0.05$, T cells versus the preceding day after inoculation; ${ }^{\dagger} P \leq 0.05$ for monocytes versus the preceding day after inoculation; ${ }^{\ddagger} P \leq 0.05$ relative to the preceding day after inoculation; ${ }^{\S} P \leq 0.05$ for infected animals at all time points relative to uninfected macaques. 
uninfected macaques. Although not significantly changed, there was a trend toward a decline in peripheral blood monocytes during acute infection at $7 \mathrm{dpi}(P=0.06)$. This was followed by an increase in monocytes within the blood during asymptomatic disease at 14 dpi (Figure 4D). This number restored to basal levels at day 10 , before increasing again during chronic disease at 56 dpi (Figure 4D).

The increase in spleen monocytes that we observed using flow cytometry was confirmed with NanoString analyses, as there was a twofold increase in CD14 in the spleen of infected macaques as compared to uninfected animals (Figure 4C). To characterize the mechanisms that might contribute to this increase in spleen monocytes, we analyzed our NanoString data focusing on monocyte chemokines and chemokine receptors. There was a pronounced production of chemokine ligand (CCL) 8 during SIV infection, relative to controls (Figure 5A). With an almost 200-fold increase, CCL8 was the predominant monocyte chemokine produced in the spleen. Even when approaching terminal disease, there was still a 15 -fold increase in CCL8 as compared to uninfected macaques (Figure 5A). Although produced to a much lower extent than CCL8, additional monocyte chemokines were also significantly increased in the spleen as a result of SIV infection, including CCL7 (Figure 5B), CCL2 (Figure 5C), CXCL2 (Figure 5D), CXCL3 (Figure 5E), and CCL5 (Figure 5F). There was also up-regulation of the chemokine receptors CCR1 (receptor to CCL8, CCL7, and CCL5) (Figure 5G), CCR2 (receptor to CCL2, CCL7, and CCL8) (Figure 5H), and to a lesser extent, CCR5 (receptor to CCL5 and CCL8) (Figure 5I). These data suggest that monocytes accumulate within the spleen during SIV infection in response to the up-regulation of monocyte chemoattractants and chemokine receptors that promote the recruitment of peripheral blood derived cells.

\section{SIV-Infected CD163, CD68, and Mac387 Macrophages Are Primarily Present in the Red Pulp}

To determine the extent to which macrophages contributed to SIV replication in the spleen, we performed single color
A

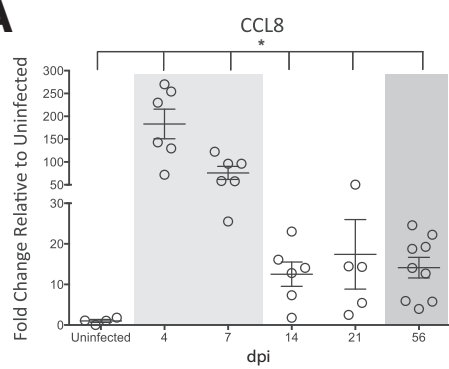

D

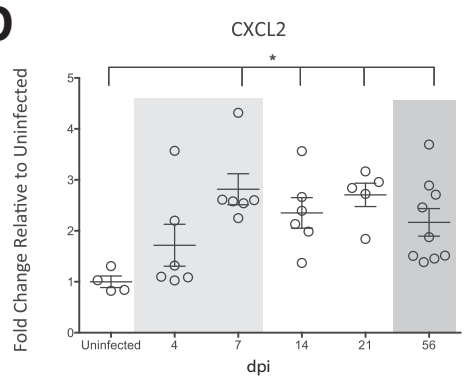

G

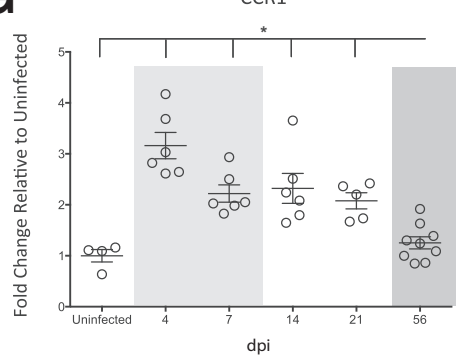

B

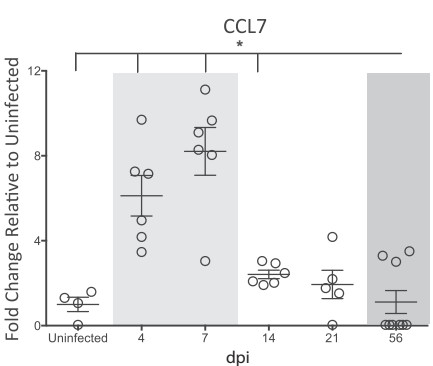

E

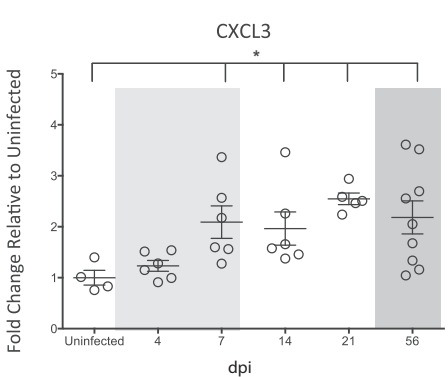

H

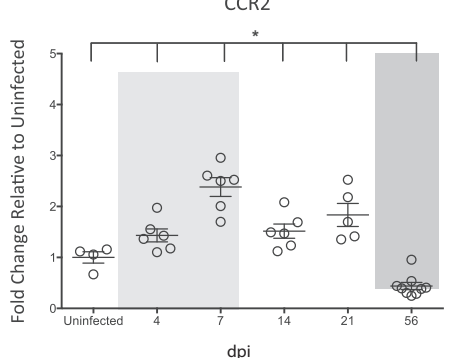

C

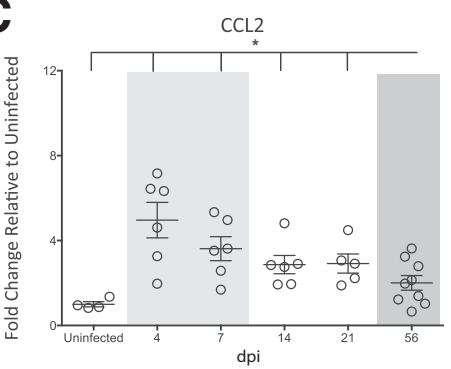

$\mathbf{F}$

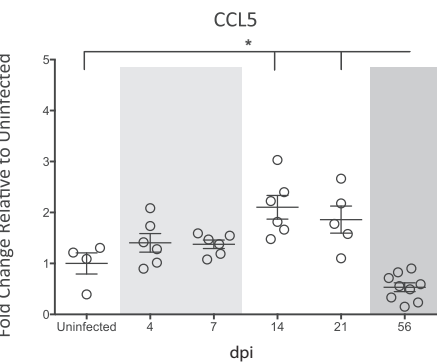

I

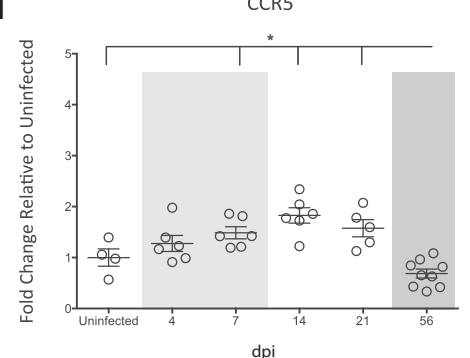

Figure 5 Expression of monocyte chemoattractants and chemokine receptors. RNA was isolated from the spleen of uninfected macaques and at 4, 7, 14, 21, and $56 \mathrm{dpi}$ and gene expression analyses performed by NanoString barcoding technology. The relative counts of each gene product were determined on normalizing to four housekeeping genes. The fold-change of each gene was determined relative to uninfected controls, which was set to 1 . The longitudinal fold-changes in chemokine ligand (CCL) 8 (A), CCL7 (B), CCL2 (C), CXCL2 (D), CXCL3 (E), CCL5 (F), CCR1 (G), CCR2 (H), and CCR5 (I) in the spleen are shown. The acute (light shading), asymptomatic, and chronic (dark shading) phases of SIV infection are depicted. Statistical significance was determined by Kruskal-Wallis analysis of variance test followed by Dunn's multiple comparison analysis. Vertical lines indicate a significant difference between the indicated dpi and uninfected animals, as determined by the Dunn's multiple comparison analysis. Data are expressed as means \pm SD. ${ }^{*} P \leq 0.05$ for infected animals at all time points relative to uninfected macaques. 

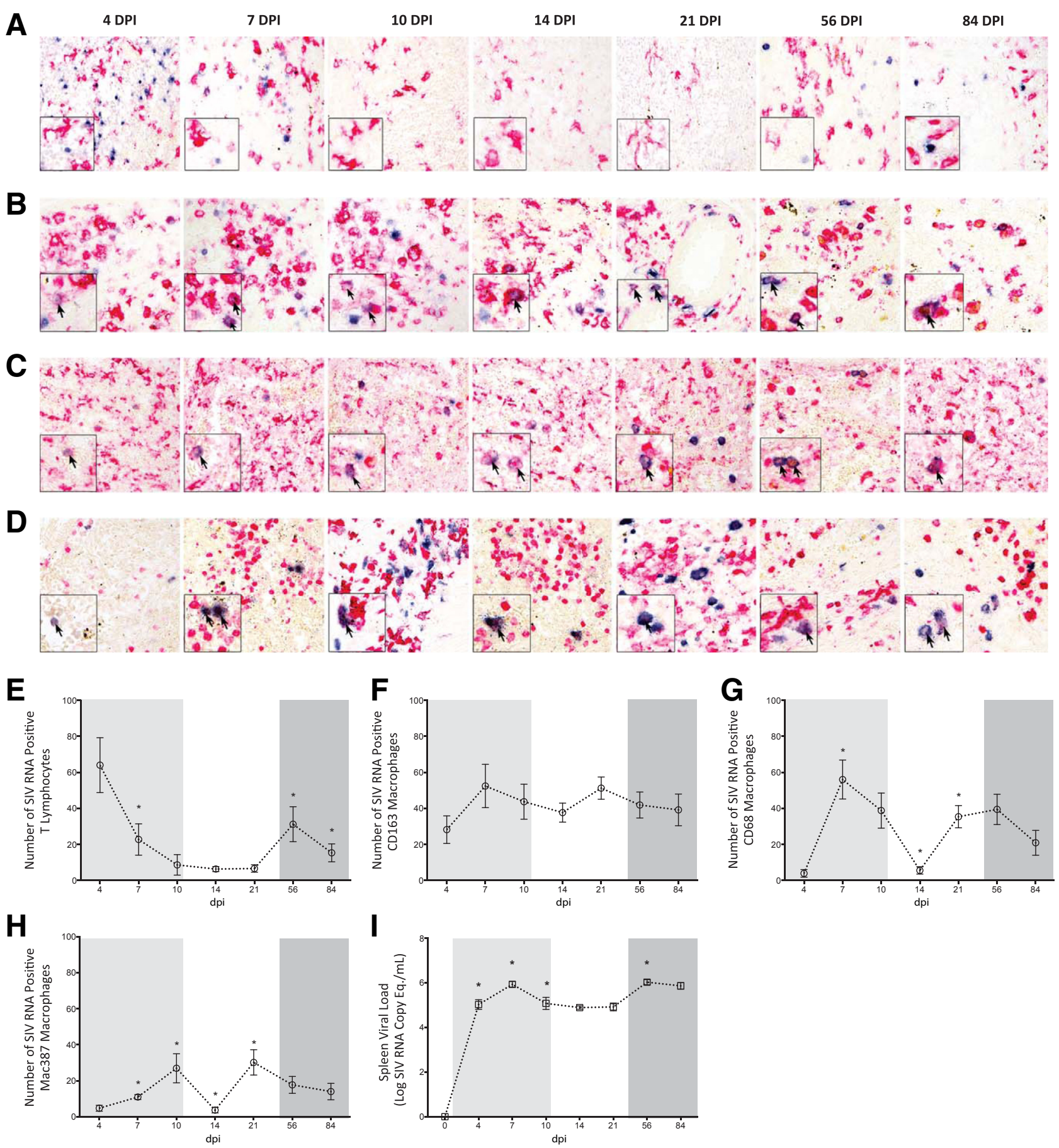

Figure 6 Determination of macrophage infection in red and white pulp. Immunohistochemistry with in situ hybridization were performed on spleen sections at $4,7,10,14,21,56$, and 84 dpi to identify SIV RNA positive (blue staining) macrophages. Representative images demonstrate CD163 macrophages in the white (A) and red pulp (B), CD68 red pulp macrophages (C), and Mac387 red pulp macrophages (D). Red staining indicates the respective macrophage populations. Blue staining indicates SIV RNA. Boxed insets show higher magnification of macrophages in the white (A) and red (B-D) pulp. SIV RNA positive macrophages are indicated by arrows. The absolute number of SIV RNA positive T lymphocytes in the white pulp (E) and red pulp CD163 (F), CD68 (G), and Mac387 (H) macrophages in five random fields was determined. I: RNA was isolated from spleen tissue and viral load determined by quantitative RT-PCR. The acute (light shading), asymptomatic, and chronic (dark shading) phases of SIV infection are depicted. Dashed lines connecting data points indicate crosssectional study of independent groups of animals after euthanasia at each time point. Statistical significance was determined by Mann-Whitney test. Data are expressed as means $\pm S D$. ${ }^{*} P \leq 0.05$ versus the preceding day after inoculation. Original magnification: $\times 20(\mathbf{A}-\mathbf{D}$, main images); $\times 40$ (A-D, insets)

immunohistochemistry for CD163, CD68, or Mac387 with tandem in situ hybridization. We calculated the number of SIV RNA positive macrophages in five random fields of spleen at 4, 7, 10, 14, 21, 56, and 84 dpi. We first analyzed the white pulp, which is composed of both $\mathrm{T}$ lymphocytes and macrophages. Analysis of the white pulp indicated that none of the in situ positive cells colocalized with the much larger and morphologically complex CD163 macrophages 
(Figure 6A). The in situ positive cells in the white pulp also failed to colocalize with the immunochemistry stains for CD68 or Mac387 macrophages (data not shown). In contrast to the cells that were positive for any of the macrophage immunohistochemistry markers, the white pulp in situ positive cells were small and punctate (Figure 6A), and were likely $\mathrm{T}$ lymphocytes. These cells were quantitated, and during early infection (4 dpi) when considerable SIV RNA was produced $(5.03 \pm 0.21 \log$ SIV RNA copy eq./mL) (Figure 6I), there were also a large number of SIV RNA positive $\mathrm{T}$ lymphocytes in the white pulp (Figure 6E), as evidenced by intense blue staining (Figure 6A). However, the number of in situ positive $\mathrm{T}$ lymphocytes dramatically decreased at 7 dpi $(22.76 \pm 8.68)$, as compared to those present at $4 \mathrm{dpi}(64.00 \pm 15.21)$ (Figure 6E). This substantial reduction in in situ positive T lymphocytes at $7 \mathrm{dpi}$ was easily discernable on visual examination (Figure 6A). SIV RNA positive $\mathrm{T}$ lymphocytes continued to occur at relatively low levels in the white pulp throughout the remainder of acute infection and into the asymptomatic phase (Figure 6, A and E).

Although there was a moderate increase in the number of in situ positive T cells at $56 \mathrm{dpi}$, this was short-lived, as SIV RNA positive T lymphocytes declined by 84 dpi (Figure $6 \mathrm{E}$ ). Despite being in close proximity to the in situ positive $\mathrm{T}$ lymphocytes, SIV RNA was rarely observed in CD163 (Figure 6A), CD68, or Mac387 (data not shown) white pulp macrophages. In contrast to the follicle, macrophages comprised the predominant SIV RNA positive cells in the red pulp. CD163 macrophages were the major cells that were in situ positive in this area of the spleen and were readily observed at every examined time point during infection (Figure 6B). SIV RNA positive CD163 macrophages were widely distributed in the red pulp, and most frequently occurred in dense clusters of SIV infected cells in close proximity to each other. In contrast to CD163 cells, CD68 macrophages were infected in a biphasic manner. Although present early (7 and $10 \mathrm{dpi}$ ) (Figure 6C), SIV RNA positive CD68 macrophages decreased significantly at $14 \mathrm{dpi}$, and increased again later at 21 and $56 \mathrm{dpi}$ (Figure 6, C and G). At these later time points, the SIV RNA positive CD68 macrophages were more numerous and also had more intense in situ staining. In contrast, the few SIV RNA positive CD68 macrophages at 7 and 14 dpi were faintly stained, indicating a lower level of SIV RNA in the cells (Figure 6C). Although present throughout the entire red pulp, SIV RNA positive CD68 macrophages were widely scattered with only three or four positive cells present in close proximity to each other. This is in contrast to CD163 macrophages, in which SIV RNA positive cells were highly clustered.

Mac387 macrophages were also infected in a biphasic manner. Similar to the CD68 SIV positive cells, a high frequency of SIV RNA positive Mac387 macrophages were identified during acute infection at 7 and $10 \mathrm{dpi}$, which decreased in number at $14 \mathrm{dpi}$, and finally increased during asymptomatic infection at 21 dpi (Figure 6D). When the
SIV RNA positive Mac387 cells were at their highest levels, these macrophages were densely packed and occurred in close proximity to other positive cells (Figure 6D). These cells were also large and had a complex morphology. In contrast, when the Mac387 SIV RNA positive cells were less frequent, they had a smaller, rounder morphology and were not clustered (Figure 6D).

The number of SIV RNA positive CD163, CD68, and Mac387 macrophages was enumerated in five random fields of the red pulp. In addition, in situ positive T lymphocytes were quantified within the white pulp. At 4 dpi when there was robust $\mathrm{T}$ lymphocyte infection in the white pulp, macrophages comprised only a minor portion of the SIV RNA positive cells in the spleen. Of the macrophage populations, red pulp CD163 cells represented the primary subset that was in situ positive at $4 \mathrm{dpi}$, as CD68 and Mac387 macrophages were minimally infected at this time point (Figure 6, F-H). However, as white pulp infection became less prominent, likely because of the death of infected $\mathrm{T}$ cells, macrophages represented the majority of the SIV RNA positive cells in the spleen. This occurred as a result of a significant increase in the number of SIV RNA positive CD68 and Mac387 cells, which was most notable at 7, 10, and 21 dpi (Figure 6, G and H). In contrast to the other macrophage populations, SIV RNA positive CD163 cells remained consistently numerous throughout longitudinal SIV infection. In fact, CD163 macrophages represented the primary SIV RNA positive cell type in the entire spleen at $14 \mathrm{dpi}$. At this time point during the asymptomatic phase of disease, there were low numbers of in situ positive CD68 and Mac387 macrophages (Figure 6, G and H), as well as $\mathrm{T}$ lymphocytes (Figure 6E). Despite a significant decrease in the number of other cell types that were SIV RNA positive during this time, CD163 macrophages alone were sufficient to maintain SIV production, as spleen viral load was not significantly altered at $14 \mathrm{dpi}$ as compared to 10 dpi (Figure 6I). Together, these findings indicate that macrophages constitute a major cellular target of SIV in the spleen, and at certain phases of infection comprise the predominant population of infected cells in spleen.

\section{Low Levels of Apoptosis in the Red Pulp during SIV Infection}

To examine whether macrophage polarization and SIV infection promoted apoptosis, immunohistochemistry for cleaved caspase- 3 was performed on spleen sections obtained from SIV infected animals during acute, asymptomatic, and chronic stages of disease. There were no significant changes in macrophage apoptosis in white pulp, suggesting that the cell death was primarily restricted to the red pulp (data not shown). Cleaved caspase-3 immunoreactivity was minimal in uninfected control spleen; in contrast, apoptosis was detected in the red pulp during SIV infection (Figure 7A). Overall, increases in the percentage of cells with cleaved caspase-3 immunoreactivity were minimal during acute 

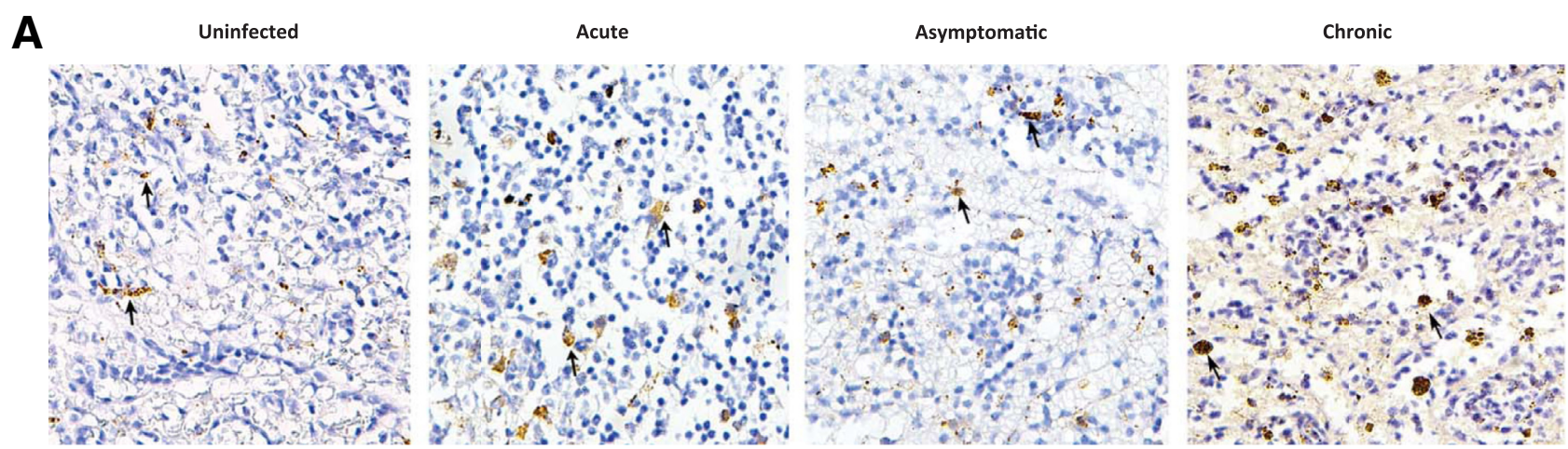

B
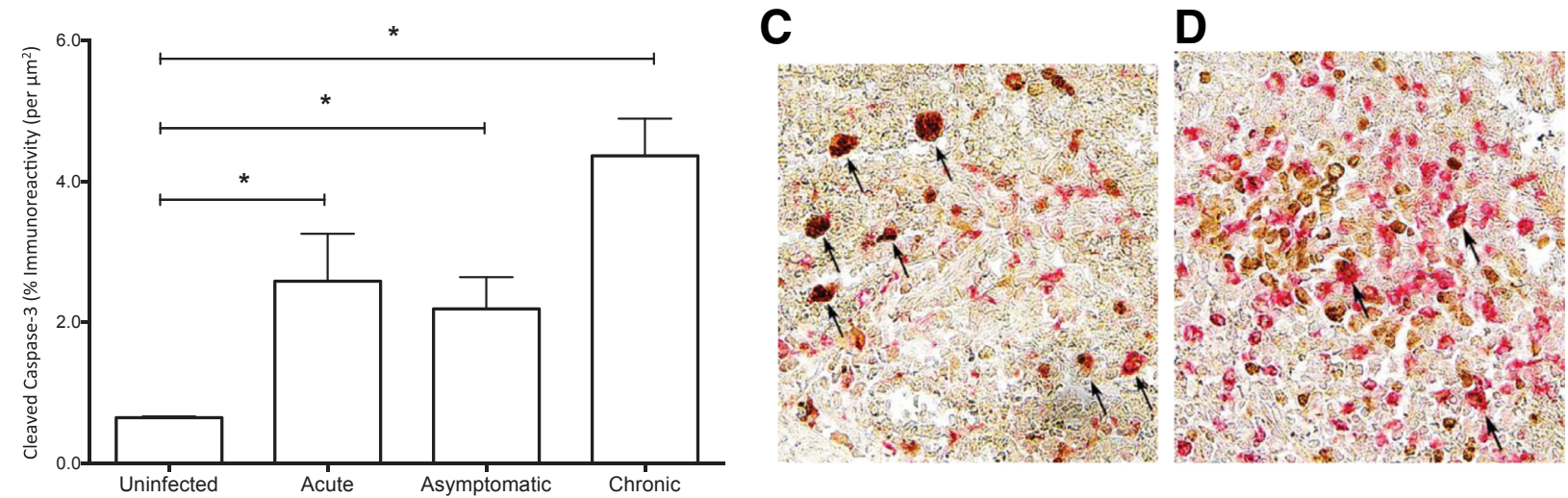

Figure 7 Quantitation of apoptotic cells in red pulp during SIV infection. A: Immunohistochemistry for cleaved caspase-3 was performed on spleen sections obtained from uninfected animals and during the acute, asymptomatic, and chronic phase of infection to identify apoptotic cells. Images from one animal, that are representative of nine examined, are shown. Brown staining indicates cleaved caspase-3, denoted by arrows. B: Quantification was performed using Nikon Elements software and the percentage of cells with cleaved caspase-3 immunoreactivity per $\mu \mathrm{m}^{2}$ within the red pulp was obtained. Spleen sections were double labeled for cleaved caspase-3 and CD68 (C) or CD163 (D). Images from one animal, representative of six animals, are shown. Cleaved caspase-3 positive CD68 (C) and CD163 (D) macrophages are indicated by arrows. Statistical significance was determined by Kruskal-Wallis analysis of variance test. Data are expressed as means \pm SD. ${ }^{*} P \leq 0.05$. Original magnification, $\times 20(\mathbf{A}, \mathbf{C}$, and $\mathbf{D})$.

$(2.58 \% \pm 0.67 \%)$, asymptomatic $(2.19 \% \pm 0.45 \%)$, and chronic $(4.36 \% \pm 0.52 \%)$ phases of SIV infection, as compared to uninfected controls $(0.65 \% \pm 0.02 \%)$ (Figure 7B). To determine whether the apoptosis occurred specifically in CD68 and/or CD163 macrophages, doublelabeled immunohistochemistry was performed for each macrophage marker and cleaved caspase-3. CD68 macrophages represented the predominant cell within the red pulp undergoing apoptosis (Figure 7C). These cells often had an enlarged, activated phenotype and lacked the extensive processes typically present on CD68 red pulp macrophages. In contrast, only a minor population of CD163 macrophages was positive for cleaved caspase-3 (Figure 7D). These data indicate that apoptosis contributes to a partial loss of CD68 red pulp macrophages during SIV infection.

\section{Discussion}

Lymphoid organs are one of the main sites of HIV replication in the human body and contribute greatly to viral production. The effects of HIV infection in the spleen have received considerably less characterization than that of other lymphoid organs, including lymph nodes and thymus. The spleen undergoes substantial morphologic alterations during HIV infection, which is characterized by hyposplenism, white pulp depletion, and germinal center burn out. This is primarily associated with decreased $\mathrm{T}$ cell and humoral immune responses. The spleen is composed not only of lymphocytes, but also contains specialized macrophages, which are highly susceptible to HIV infection and fulfill many major functions of the spleen. Despite their roles in mediating HIV persistence, few studies have focused on HIV infection of splenic macrophages.

Using our SIV macaque model, we studied longitudinal changes in macrophage subpopulations from acute to terminal stages of disease. We identified a striking global up-regulation of CD163 in macrophages in both the red and white pulp, which occurred with a concomitant decrease in CD68 positive macrophages. In addition, there was a rapid depletion of fetal-derived $\mathrm{CD} 163^{+} \mathrm{CD}^{+} 8^{+}$red pulp macrophages, which occurred, in part, because of apoptosis of these cells that preceded a loss of higher-order structure and splenic integrity. The loss of CD68 and $\mathrm{CD} 163^{+} \mathrm{CD} 68^{+}$ macrophages and increase in CD163 cells occurred early during the acute phase of infection, and persisted until terminal disease. In addition to these long-lasting changes, there was also a transient, significant influx of Mac387 
macrophages and peripheral blood-derived monocytes into the spleen during the asymptomatic phase of infection. The newly recruited monocytes may have contributed to splenic macrophage subsets on differentiation, as they expressed high levels of the activation/maturation marker CD16. However, monocyte recruitment was not sufficient to restore splenic macrophage subsets to those present before infection. A schematic representation of SIV-induced changes in macrophage populations in spleen is depicted in Figure 8.

Whole-organ, gene expression analyses demonstrated that the profound changes in splenic macrophages occurred, at least in part, because of an up-regulation of interferon and interferon-stimulated genes, M2 macrophage polarization genes, and monocyte/macrophage chemokines and chemokine receptor signaling. With an approximately 200 -fold increase relative to uninfected macaques, the monocyte/macrophage chemoattractant CCL8 was the most differentially regulated transcript during SIV infection. Because the NanoString analyses were performed using homogenates of whole spleen, rather than RNA isolated from purified cell populations, we cannot determine which cells produced our observed changes in interferon, M2 polarizing, and chemokine and chemokine receptor genes. In situ hybridization analyses for SIV RNA demonstrated that CD163, CD68, and Mac387 macrophages were highly infected. Macrophage subsets were in situ positive even when $\mathrm{T}$ lymphocytes no longer expressed SIV RNA. This direct comparison of infection of lymphocytes and macrophages demonstrates that macrophages had a significant impact on SIV replication in spleen and were sufficient to maintain viral production in the absence of $\mathrm{T}$ cells. Our findings provide strong evidence that SIV promotes irreparable damage to the splenic mononuclear phagocyte system, and that splenic pathogenesis is largely driven by alterations and infection of macrophage subsets, which begins early after infection and is sustained until end-stage disease.

Our comprehensive analyses provided the examination of splenic $\mathrm{T}$ cell populations and morphology concurrent with our macrophage analyses. We confirmed that substantial splenic morphologic changes occurred during SIV infection, which has been observed previously during HIV/SIV infection. $^{2}$ The most prominent morphologic finding was lymphoid depletion, characterized by a reduced, disrupted follicular architecture. Flow cytometry confirmed the histological finding of lymphoid depletion, as there was a decrease in the frequency of $\mathrm{CD}^{+} \mathrm{T}$ cells. Longitudinal analysis enabled further characterization of splenic $\mathrm{T}$ cell subsets during SIV infection. During acute infection there were dysregulated CD4/CD8 ratios, markers of cellular activation, and memory/effector subsets, as compared to that present in uninfected counterparts. With the exception of cellular activation, $\mathrm{T}$ cell subset profiles resolved and were restored to levels similar to that of uninfected animals by terminal disease. This provides a more complete

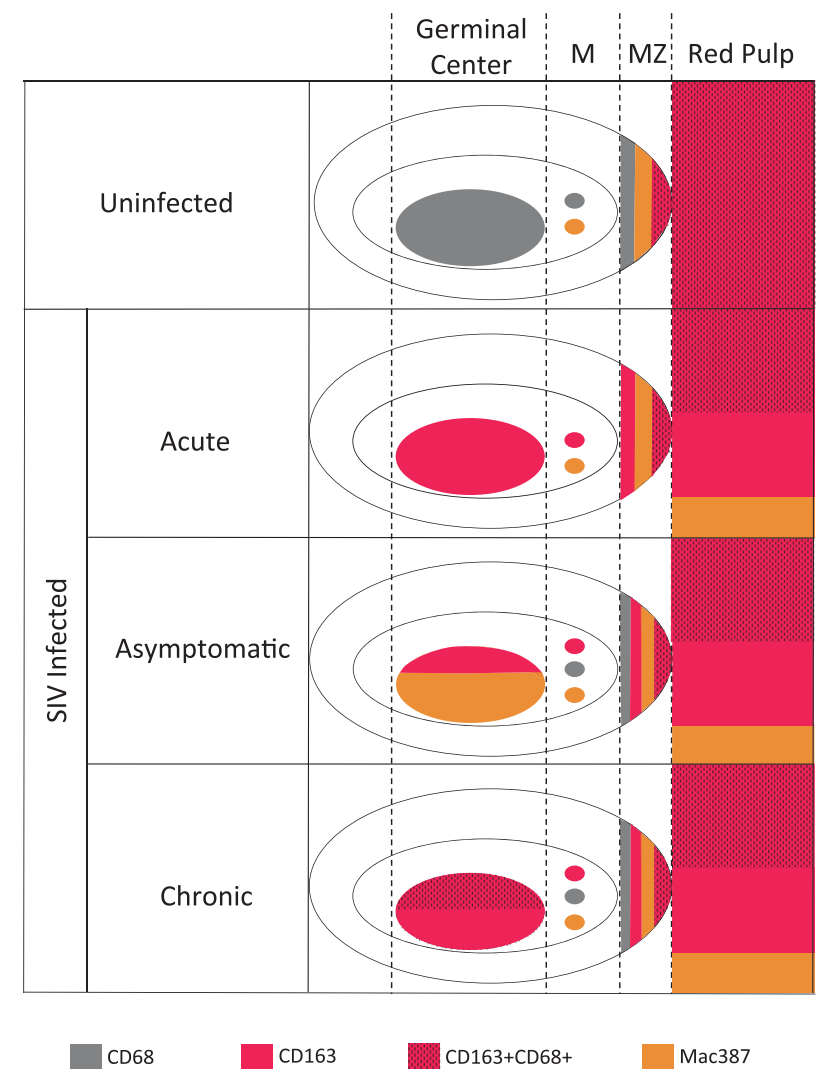

Figure 8 Schematic representation of changes in macrophage populations in spleen during longitudinal SIV infection. During homeostasis in the uninfected spleen, $\mathrm{CD} 68$ and $\mathrm{CD}_{163}{ }^{+} \mathrm{CD} 68^{+}$cells represent the predominant macrophage subsets in the germinal center and red pulp, respectively. Although relatively devoid of macrophages, the mantle zone (M) primarily consists of $\mathrm{CD} 68$ and Mac387 cells. There are numerous CD68, $\mathrm{CD}_{163}{ }^{+} \mathrm{CD} 8^{+}$, and Mac387 cells in the macrophage-rich marginal zone (MZ). Within this area of the spleen, the CD68 cells reside in closer proximity to the mantle zone, whereas the $\mathrm{CD} 163^{+} \mathrm{CD} 68^{+}$macrophages are proximal to the red pulp. Macrophages undergo changes in polarization and substantially alter their expression of cell markers after SIV infection. During the acute phase of infection, there is a global up-regulation of CD163 throughout the entire spleen. In contrast, there is a simultaneous and substantial decrease in CD68 macrophages. In addition, CD163 and Mac387 cells replace the fetal-derived $\mathrm{CD}_{163}{ }^{+} \mathrm{CD} 68^{+}$macrophages in the red pulp in the acute phase. During asymptomatic infection, peripheral blood monocytes are recruited into the spleen and rapidly disseminate to the germinal center. A limited recovery of CD68 macrophages in the mantle and marginal zones happens during this time. The dysregulation of mantle zone, marginal zone, and red pulp macrophages are maintained during chronic and late-stage infection. Notably during this late time, $\mathrm{CD}_{163}{ }^{+} \mathrm{CD}_{68}{ }^{+}$macrophages become present in the germinal center, perhaps as a final compensatory mechanism in an effort to recover the CD68 cells that were lost acutely. Therefore, macrophages are altered in every area of the spleen during SIV infection, and never fully recover to the previous state found in uninfected animals.

understanding of HIV/SIV-induced changes in splenic T cell populations. In addition, our findings underline the importance of longitudinal study. Although T cell activation was previously implicated in spleen pathology during acute SIV infection, ${ }^{81}$ many studies have been limited to crosssectional analysis, which does not completely capture the dynamic nature of $\mathrm{T}$ cell responses. The transient changes in 
$\mathrm{T}$ cell populations in the spleen provide further support to the substantial contribution of macrophages in promoting splenic destruction, as their SIV-induced fluctuations remained present until end-stage disease.

Differential regulation of macrophage expression of CD68 and CD163 has great implications for splenic function and integrity in the context of HIV infection. Decreased macrophage functional markers were shown to impair the activation of these cells, which promoted an abrogation of their filter functions and was associated with splenic pathology, poor clinical outcomes, and AIDS-defining opportunistic infections in HIV seropositive individuals. ${ }^{18}$ It is unclear whether CD68 and CD163 dysregulations resulted from changes in the relative frequencies of these macrophage populations, transit of cells from spleen, or whether differential expression of these macrophage markers occurred. Rapid changes in macrophage expression of CD68 and CD163 can occur on polarization with appropriate stimuli. In support of this, our NanoString data indicated a skewing toward M2 polarization, suggesting that our observed change in immunochemistry signal was because of the regulation in expression of these markers. However, morphologic analyses indicated that the number of red pulp macrophages also decreased, as evidenced by irregularly shaped cells, increased cellularity, and notable gaps in $\mathrm{CD} 163^{+} \mathrm{CD} 68^{+}$macrophages within this area of the spleen. This loss of red pulp macrophages was partially mediated by apoptosis of CD68 cells. However, $<5 \%$ of cells in the red pulp were apoptotic. We therefore hypothesize that both M2 polarization within the white pulp, and cell death of a subpopulation of red pulp macrophages, contributed to the overall loss of CD68 and increase in CD163 immunochemistry signal. Regardless of the mechanisms by which the alterations occurred, a shifting of the $\mathrm{CD} 68$ and $\mathrm{CD}_{163}{ }^{+} \mathrm{CD}^{+} 8^{+}$macrophages to a $\mathrm{CD} 163$ phenotype has functional implications in the ability of these cells to control opportunistic infections, mount adaptive immune responses, clear damaged erythrocytes, and scavenge iron, deficits which are associated with HIV infection. In addition, apoptosis of red pulp CD68 macrophages has implications for splenic function as these cells are of embryonic origin and once lost, have limited potential for restoration during adulthood.

In addition to the changes in CD68 and CD163, there was a significant increase in Mac387 macrophages in the spleen during SIV infection, which was primarily restricted to the asymptomatic phase of disease. In agreement with our finding of a temporal restriction of Mac387 cells, newly disseminated Mac387 macrophages were shown to occur transiently in the lymph nodes of SIV-infected macaques. ${ }^{82}$ This suggests that Mac387 macrophages enter into tissues after high levels of viremia, and may be an indicator of early SIV/HIV-mediated damage. Newly infiltrated splenic Mac387 macrophages may be deleterious, as they promote lymphoid destruction, viremia, and pathology. ${ }^{82,83}$ Alternatively, the recruitment of these cells may represent a protective response, in an attempt to mitigate the loss of and changes to CD68 and CD163 macrophage populations during SIV infection.

Peripheral blood monocytes were also recruited to the spleen after infection. Our gene expression data indicate that a temporal production of monocyte chemokines and chemokine receptors regulated the influx of these cells into the spleen. CCL8 was the most prominently increased chemokine relative to uninfected controls, although other chemoattractants were also significantly produced. Flow cytometric analysis demonstrated that upon entering into the spleen, the newly infiltrated monocytes expressed high levels of the activation/maturation marker CD16, suggesting that they were primed for macrophage differentiation. In support of this, CD16 monocytes were shown to be precursors for CD163 macrophages and were associated with HIV disease progression. ${ }^{84}$ This suggests that newly infiltrated monocytes may directly contribute to the increase in CD163 cells.

CD68, CD163, and Mac387 macrophages were all susceptible to SIV infection. However, their patterns of infectivity differed. Mac387 cells had the lowest rates of infection, which may have occurred because they are monocytederived cells, and are the most immature of all of the splenic macrophage subsets. Monocyte susceptibility to HIV increases with maturation and on macrophage differentiation. ${ }^{85}$ CD68 macrophages were more permissive to SIV than Mac387 cells, but their infection was temporally regulated. CD163 cells were distinct from the other macrophage subsets as they were highly susceptible to SIV and incredibly resilient in their level of infection. Remarkably, CD163 cells maintained high levels of infection even when there was a significant decrease in splenic viral load, and when the other macrophages were infected at low levels.

$\mathrm{T}$ cells were minimally infected, as compared to CD163 macrophages, and were highly infected only during acute infection. The numbers of SIV RNA positive $\mathrm{T}$ cells significantly decreased after acute infection and continued to remain low for the remainder of the disease. When present, $\mathrm{T}$ cell infection occurred primarily within the follicles of the white pulp. This is in contrast to macrophages that were predominantly infected in the red pulp. The localized restriction of SIV RNA expression for the two cell types indicates that SIV infection of myeloid cells in spleen occurred independently of $\mathrm{T}$ cells. The red pulp comprises almost $80 \%$ of the spleen, ${ }^{86,87}$ and macrophage infection within this compartment contributes greatly to the burden of virus within the organ and potentially viral load in plasma. In addition, red pulp macrophages constitute a source of prolonged viral production, as infected macrophages are not effectively killed by cytotoxic T lymphocytes. Even though SIV-specific cytotoxic T lymphocytes are numerous within the red pulp, ${ }^{88}$ they do not efficiently promote macrophage death. ${ }^{89}$ In addition to contributing to SIV infection in the spleen, macrophages are immune to the cytopathic effects of HIV/SIV and may represent a source of latent virus. Our data represent a minimum estimate of the contribution of macrophages to SIV infection in the spleen because of the 
method used to quantitate infected cells, further underlining the importance of macrophages in HIV/SIV infection.

As a result of virus infection, expression of type I interferons was increased in the spleen during SIV infection. IFN- $\beta$ was significantly increased early after infection, and although still elevated at terminal disease relative to uninfected animals, was present to a much lower extent than it was during acute disease. This same expression pattern occurred for many of the interferon stimulated genes, including MxA, IRF7, STAT2, and SOCS1. This finding of robust interferon responses early during infection is consistent with our previous work that focused on the brain. ${ }^{59}$ Although IFN- $\alpha$ is typically produced in concert with and to a similar magnitude as IFN- $\beta$, we found that it was only minimally produced during SIV infection. IL-10 may have directly resulted in a silencing of IFN- $\alpha$ and its interferon-stimulated gene IL-12, ${ }^{74,90}$ as we found that the immunosuppressive cytokine was highly produced in the spleen. We previously demonstrated that the expression of IFN- $\beta$ and IL-10 occurred without a concomitant upregulation of IFN- $\alpha$ in the central nervous system. ${ }^{59,60,91}$ Our current work supports this, and we now postulate that limited IFN- $\alpha$ production occurs because of a macrophagedriven, rather than $\mathrm{T}$ cell, pathogenesis. Furthermore, we hypothesize that a hindrance of IFN- $\alpha$ responses occurs in tissues in which HIV/SIV infection primarily occurs in myeloid cells, including brain and spleen.

Similar to IFN- $\alpha$, the interferon stimulated gene SOCS3 did not have the same expression pattern of IFN- $\beta$. Instead, SOCS3 maintained a consistent increase over uninfected controls at every examined time point after inoculation. This persistent up-regulation of SOCS3 may directly contribute to the increase in CD163 macrophages, as its expression in myeloid cells promotes M2 polarization and an antiinflammatory phenotype. ${ }^{92}$ Our Nanostring data indicated that the increased production of M2 polarizing cytokines IL10, IDO-1, CXCL10, and IL-27 may also have contributed to a shift in macrophage phenotype. There was also a persistent down-regulation of the M1 gene $I l 12 b$ and a failure to induce M1-associated cytokines, which provides further support of a SIV-induced M2 macrophage polarization phenotype. Spleen-derived macrophages transiently polarize when exposed to M1 or M2-inducing substances, and revert back to a resting phenotype upon removal of the stimuli. $^{93}$ This plasticity is of paramount importance in restoring homeostasis after cellular activation and on pathogen clearance. As M2 cells are of an anti-inflammatory nature, a perpetual M2 macrophage phenotype may compromise the ability of the spleen to elicit an appropriate inflammatory response on exposure to pathogens - a function that is integral to the blood filtering functions of the organ. The balance of M1/M2 polarization may also directly affect viral production in the spleen. Macrophage CD163 expression, an indicator of $\mathrm{M} 2$ polarization, was shown to promote the HIV infectivity of these cells. ${ }^{94}$ The implications of this were demonstrated in an in vivo setting, where
CD163 macrophages directly contributed to viral burden in both heart $^{95}$ and brain. ${ }^{96}$ In addition, polarization is extremely important as it shifts macrophages from a state of active to latent viral infection. ${ }^{97} \mathrm{~A}$ model was proposed in which macrophages changed from M1 to M2 polarization during the transition from early to late stage disease, which promoted their latent infection and the formation of a steady-state viral reservoir. ${ }^{98}$ The loss of a polarized phenotype promoted active macrophage viral replication and the production of infectious virus, ${ }^{97}$ suggesting that polarization-reversing agents must be considered when developing shock and kill therapeutic strategies.

HIV/SIV infection of the spleen is not only important for this organ, but also has consequences for other macrophagerich organs. We previously demonstrated that viral sequences that originated in the spleen later presented in the brain, suggesting that the spleen may facilitate new or reinfection of other areas of the body that were previously uninfected or virologically quiescent. ${ }^{58}$ This might occur through the transit of splenic monocytes into peripheral circulation. ${ }^{99,100}$ Monocytes that resided in the spleen were exposed to microbial infection while present in this organ, and upon efflux into distal sites promoted widespread pathogen dissemination. As the Trojan Horse nature of these cells is implicated in viral seeding, controlling SIV/HIV infection of the spleen must be considered when developing HIV cure strategies. Our findings indicate that macrophages are a long-lasting and major cellular target for HIV/SIV in the spleen, and that these cells drive splenic pathology. Therapeutic strategies must also focus on restoring macrophage populations and functions, and limiting their infection to maintain splenic homeostasis during HIV infection.

\section{Acknowledgment}

We thank all of the members of the retrovirus laboratory for their valuable insights and helpful discussions.

\section{Supplemental Data}

Supplemental material for this article can be found at http://dx.doi.org/10.1016/j.ajpath.2016.03.019.

\section{References}

1. Nyberg M, Suni J, Haltia M: Isolation of human immunodeficiency virus (HIV) at autopsy one to six days postmortem. Am J Clin Pathol 1990, 94:422-425

2. Diaz LK, Murphy RL, Phair JP, Variakojis D: The AIDS autopsy spleen: a comparison of the pre-anti-retroviral and highly active antiretroviral therapy eras. Mod Pathol 2002, 15:406-412

3. Jung A, Maier R, Vartanian J-P, Bocharov G, Jung V, Fischer U, Meese E, Wain-Hobson S, Meyerhans A: Recombination: multiply infected spleen cells in HIV patients. Nature 2002, 418:144

4. Deeks SG, Autran B, Berkhout B, Benkirane M, Cairns S, Chomont N, Chun T-W, Churchill M, Di Mascio M, Katlama C: 
Towards an HIV cure: a global scientific strategy. Nat Rev Immunol 2012, 12:607-614

5. Costiniuk CT, Jenabian M-A: HIV reservoir dynamics in the face of highly active antiretroviral therapy. AIDS Patient Care STDs 2015, 29:55-68

6. Di Mascio M, Srinivasula S, Bhattacharjee A, Cheng L, Martiniova L, Herscovitch P, Lertora J, Kiesewetter D: Antiretroviral tissue kinetics: in vivo imaging using positron emission tomography. Antimicrob Agents Chemother 2009, 53:4086-4095

7. McElrath MJ, Steinman RM, Cohn ZA: Latent HIV-1 infection in enriched populations of blood monocytes and T cells from seropositive patients. J Clin Invest 1991, 87:27

8. Doitsh G, Galloway NLK, Geng X, Yang Z, Monroe KM, Zepeda O, Hunt PW, Hatano H, Sowinski S, Munoz-Arias I, Greene WC: Cell death by pyroptosis drives CD4 T-cell depletion in HIV-1 infection. Nature 2014, 505:509-514

9. Okoye AA, Picker LJ: CD4+ T-cell depletion in HIV infection: mechanisms of immunological failure. Immunol Rev 2013, 254: 54-64

10. Doitsh G, Cavrois M, Lassen KG, Zepeda O, Yang Z, Santiago ML, Hebbeler AM, Greene WC: Abortive HIV infection mediates CD4 T cell depletion and inflammation in human lymphoid tissue. Cell 2010, 143:789-801

11. Williams KC, Burdo TH: HIV and SIV infection: the role of cellular restriction and immune responses in viral replication and pathogenesis. APMIS 2009, 117:400-412

12. Nie C, Sato K, Misawa N, Kitayama H, Fujino H, Hiramatsu H, Heike T, Nakahata T, Tanaka Y, Ito M, Koyanagi Y: Selective infection of $\mathrm{CD} 4+$ effector memory $\mathrm{T}$ lymphocytes leads to preferential depletion of memory T lymphocytes in R5 HIV-1-infected humanized NOD/SCID/IL-2R rnull mice. Virology 2009, 394:64-72

13. Sun Z, Denton PW, Estes JD, Othieno FA, Wei BL, Wege AK, Melkus MW, Padgett-Thomas A, Zupancic M, Haase AT: Intrarectal transmission, systemic infection, and CD4 $+\mathrm{T}$ cell depletion in humanized mice infected with HIV-1. J Exp Med 2007, 204:705-714

14. Boasso A, Vaccari M, Hryniewicz A, Fuchs D, Nacsa J, Cecchinato V, Andersson J, Franchini G, Shearer GM, Chougnet C: Regulatory T-cell markers, indoleamine 2,3-dioxygenase, and virus levels in spleen and gut during progressive simian immunodeficiency virus infection. J Virol 2007, 81:11593-11603

15. Mattapallil JJ, Douek DC, Hill B, Nishimura Y, Martin M, Roederer M: Massive infection and loss of memory CD4+ T cells in multiple tissues during acute SIV infection. Nature 2005, 434: 1093-1097

16. Haase A: Population biology of HIV-1 infection: viral and CD4+ T cell demographics and dynamics in lymphatic tissues. Annu Rev Immunol 1999, 17:625-656

17. Cheynier R, Henrichwark S, Hadida F, Pelletier E, Oksenhendler E, Autran B, Wain-Hobson S: HIV and T cell expansion in splenic white pulps is accompanied by infiltration of HIV-specific cytotoxic T lymphocytes. Cell 1994, 78:373-387

18. Falk S, Stutte HJ: The spleen in HIV infection: morphological evidence of HIV-associated macrophage dysfunction. Res Virol 1990, 141:161-169

19. Chun T-W, Carruth L, Finzi D, Shen X, DiGiuseppe JA, Taylor H, Hermankova M, Chadwick K, Margolick J, Quinn TC, Kuo YH, Brookmeyer R, Zeiger MA, Barditch-Crovo P, Siliciano RF: Quantification of latent tissue reservoirs and total body viral load in HIV-1 infection. Nature 1997, 387:183-188

20. Rappaport J, Volsky D: Role of the macrophage in HIV-associated neurocognitive disorders and other comorbidities in patients on effective antiretroviral treatment. J Neurovirol 2015, 21:235-241

21. Matusali G, Dereuddre Bosquet N, Le Tortorec A, Moreau M, Satie A-P, Mahé D, Roumaud P, Bourry O, Sylla N, BernardStoecklin S, Pruvost A, Le Grand R, Dejucq-Rainsford N: Detection of SIV in semen, urethra and male reproductive organs during efficient HAART. J Virol 2015, 89:5772-5787
22. Abbas W, Tariq M, Iqbal M, Kumar A, Herbein G: Eradication of HIV-1 from the macrophage reservoir: an uncertain goal? Viruses 2015, 7:1578-1598

23. Fischer T, Wyatt CM, D’Agati VD, Croul S, McCourt L, Morgello S, Rappaport J: Mononuclear phagocyte accumulation in visceral tissue in HIV encephalitis: evidence for increased monocyte/macrophage trafficking and altered differentiation. Curr HIV Res 2014, 12:201

24. Hernandez-Vargas EA, Middleton RH: Modeling the three stages in HIV infection. J Theor Biol 2013, 320:33-40

25. Pasternak AO, Lukashov VV, Berkhout B: Cell-associated HIV RNA: a dynamic biomarker of viral persistence. Retrovirology 2013, 10:41

26. Wang $\mathrm{T}$, Xu Y, Zhu H, Andrus T, Ivanov SB, Pan C, Dolores J, Dann GC, Zhou M, Forte D, Yang Z, Holte S, Corey L, Zhu T: Successful isolation of infectious and high titer human monocytederived HIV-1 from two subjects with discontinued therapy. PLoS One 2013, 8:e65071

27. Kallianpur KJ, Shikuma C, Kirk GR, Shiramizu B, Valcour V, Chow D, Souza S, Nakamoto B, Sailasuta N: Peripheral blood HIV DNA is associated with atrophy of cerebellar and subcortical gray matter. Neurology 2013, 80:1792-1799

28. Cummins N, Badley A: Anti-apoptotic mechanisms of HIV: lessons and novel approaches to curing HIV. Cell Mol Life Sci 2012, 70: $3355-3363$

29. Zhu T: HIV-1 in peripheral blood monocytes: an underrated viral source. J Antimicrob Chemother 2002, 50:309-311

30. Meltzer MS, Nakamura M, Hansen BD, Turpin JA, Kalter DC, Gendelman HE: Macrophages as susceptible targets for HIV infection, persistent viral reservoirs in tissue, and key immunoregulatory cells that control levels of virus replication and extent of disease. AIDS Res Hum Retroviruses 1990, 6:967-971

31. Koenig S, Gendelman HE, Orenstein JM, Dal Canto M, Pezeshkpour GH, Yungbluth M, Janotta F, Aksamit A, Martin MA, Fauci AS: Detection of AIDS virus in macrophages in brain tissue from AIDS patients with encephalopathy. Science 1986, 233: 1089-1093

32. Ho DD, Rota TR, Hirsch MS: Infection of monocyte/macrophages by human T lymphotropic virus type III. J Clin Invest 1986, 77:1712

33. Gartner S, Markovits P, Markovitz DM, Kaplan MH, Gallo RC, Popovic M: The role of mononuclear phagocytes in HTLV-III/LAV infection. Science 1986, 233:215-219

34. Duncan CJ, Williams JP, Schiffner T, Gärtner K, Ochsenbauer C, Kappes J, Russell RA, Frater J, Sattentau QJ: High-multiplicity HIV1 infection and neutralizing antibody evasion mediated by the macrophage-T cell virological synapse. J Virol 2014, 88:2025-2034

35. Costiniuk CT, Jenabian M-A: Cell-to-cell transfer of HIV infection: implications for HIV viral persistence. J Gen Virol 2014, 95: 2346-2355

36. Alexaki A, Liu Y, Wigdahl B: Cellular reservoirs of HIV-1 and their role in viral persistence. Curr HIV Res 2008, 6:388

37. Carr J, Hocking H, Li P, Burrell C: Rapid and efficient cell-to-cell transmission of human immunodeficiency virus infection from monocyte-derived macrophages to peripheral blood lymphocytes. Virology 1999, 265:319-329

38. Crowe SM, Mills J, Elbeik T, Lifson JD, Kosek J, Marshall JA, Engleman EG, McGrath MS: Human immunodeficiency virusinfected monocyte-derived macrophages express surface gp120 and fuse with CD4 lymphoid cells in vitro: a possible mechanism of T lymphocyte depletion in vivo. Clin Immunol Immunopathol 1992, 65:143-151

39. Crowe S, Mills J, Kirihara J, Boothman J, Marshall J, McGrath M: Full-length recombinant CD4 and recombinant gp120 inhibit fusion between HIV infected macrophages and uninfected CD4-expressing T-lymphoblastoid cells. AIDS Res Hum Retroviruses 1990, 6: $1031-1037$

40. Bronte V, Pittet Mikael J: The spleen in local and systemic regulation of immunity. Immunity 2013, 39:806-818 
41. Davies LC, Jenkins SJ, Allen JE, Taylor PR: Tissue-resident macrophages. Nat Immunol 2013, 14:986-995

42. Cesta MF: Normal structure, function, and histology of the spleen. Toxicol Pathol 2006, 34:455-465

43. den Haan JM, Martinez-Pomares L: Macrophage heterogeneity in lymphoid tissues. Semin Immunopathol 2013, 35:541-552

44. Högger P, Dreier J, Droste A, Buck F, Sorg C: Identification of the integral membrane protein RM3/1 on human monocytes as a glucocorticoid-inducible member of the scavenger receptor cysteinerich family (CD163). J Immunol 1998, 161:1883-1890

45. Gordon S: Homeostasis: a scavenger receptor for haemoglobin. Curr Biol 2001, 11:R399-R401

46. Holness C, Simmons D: Molecular cloning of CD68, a human macrophage marker related to lysosomal glycoproteins. Blood 1993 , $81: 1607-1613$

47. Zwadlo G, Voegeíi R, Osthoff KS, Sorg C: A monoclonal antibody to a novel differentiation antigen on human macrophages associated with the down-regulatory phase of the inflammatory process. Pathobiology 1987, 55:295-304

48. Porcheray F, Viaud S, Rimaniol AC, Leone C, Samah B, DereuddreBosquet N, Dormont D, Gras G: Macrophage activation switching: an asset for the resolution of inflammation. Clin Exp Immunol 2005, $142: 481-489$

49. Gordon S, Plüddemann A, Martinez Estrada F: Macrophage heterogeneity in tissues: phenotypic diversity and functions. Immunol Rev 2014, 262:36-55

50. Brandtzaeg P, Flavell DJ, Fagerhol MK: Mac 387 antibody and detection of formalin resistant myelomonocytic L1 antigen. J Clin Pathol 1988, 41:963-970

51. Soulas C, Conerly C, Kim W-K, Burdo TH, Alvarez X, Lackner AA, Williams KC: Recently infiltrating MAC387+ monocytes/macrophages. Am J Pathol 2011, 178:2121-2135

52. Lichtnekert J, Kawakami T, Parks WC, Duffield JS: Changes in macrophage phenotype as the immune response evolves. Curr Opin Pharmacol 2013, 13:555-564

53. Committee for the Update of the Guide for the Care and Use of Laboratory Animals; National Research Council: Guide for the Care and Use of Laboratory Animals: Eighth Edition. Washington, DC, National Academies Press, 2011

54. Zink MC, Suryanarayana K, Mankowski JL, Shen A, Piatak M, Spelman JP, Carter DL, Adams RJ, Lifson JD, Clements JE: High viral load in the cerebrospinal fluid and brain correlates with severity of simian immunodeficiency virus encephalitis. J Virol 1999, 73: 10480-10488

55. Zink MC, Clements JE: A novel simian immunodeficiency virus model that provides insight into mechanisms of human immunodeficiency virus central nervous system disease. J Neurovirol 2002, 8: $42-48$

56. Zink MC, Brice AK, Kelly KM, Queen SE, Gama L, Li M, Adams RJ, Bartizal C, Varrone J, Rabi SA, Graham DR, Tarwater PM, Mankowski JL, Clements JE: Simian immunodeficiency virus-infected macaques treated with highly active antiretroviral therapy have reduced central nervous system viral replication and inflammation but persistence of viral DNA. J Infect Dis 2010, 202:161-170

57. Dinoso JB, Rabi SA, Blankson JN, Gama L, Mankowski JL, Siliciano RF, Zink MC, Clements JE: A simian immunodeficiency virus-infected macaque model to study viral reservoirs that persist during highly active antiretroviral therapy. J Virol 2009, 83:9247-9257

58. Ravimohan S, Gama L, Engle EL, Zink MC, Clements JE: Early emergence and selection of a SIV-LTR C/EBP site variant in SIVinfected macaques that increases virus infectivity. PLoS One 2012, 7:e42801

59. Witwer KW, Gama L, Li M, Bartizal CM, Queen SE, Varrone JJ, Brice AK, Graham DR, Tarwater PM, Mankowski JL, Zink MC, Clements JE: Coordinated regulation of SIV replication and immune responses in the CNS. PLoS One 2009, 4:e8129
60. Zaritsky LA, Gama L, Clements JE: Canonical type I IFN signaling in simian immunodeficiency virus-infected macrophages is disrupted by astrocyte-secreted CCL2. J Immunol 2012, 188: 3876-3885

61. Carruth LM, Christine Zink M, Tarwater PM, Miller MD, Li M, Queen LA, Mankowski JL, Shen A, Siliciano RF, Clements JE: SIV-specific T lymphocyte responses in PBMC and lymphoid tissues of SIV-infected pigtailed macaques during suppressive combination antiretroviral therapy. J Med Primatol 2005, 34:109-121

62. Gama L, Shirk EN, Russell JN, Carvalho KI, Li M, Queen SE, Kalil J, Zink MC, Clements JE, Kallas EG: Expansion of a subset of CD14highCD16negCCR2low/neg monocytes functionally similar to myeloid-derived suppressor cells during SIV and HIV infection. J Leukoc Biol 2012, 91:803-816

63. Shinoda K, Tokoyoda K, Hanazawa A, Hayashizaki K, Zehentmeier S, Hosokawa H, Iwamura C, Koseki H, Tumes DJ, Radbruch A: Type II membrane protein CD69 regulates the formation of resting T-helper memory. Proc Natl Acad Sci U S A 2012, 109: 7409-7414

64. Simms PE, Ellis TM: Utility of flow cytometric detection of CD69 expression as a rapid method for determining poly- and oligoclonal lymphocyte activation. Clin Diagn Lab Immunol 1996, 3:301-304

65. Lindsey W, Lowdell M, Marti G, Abbasi F, Zenger V, King K, Lamb L Jr: CD69 expression as an index of T-cell function: assay standardization, validation and use in monitoring immune recovery. Cytotherapy 2007, 9:123-132

66. Pitcher CJ, Hagen SI, Walker JM, Lum R, Mitchell BL, Maino VC, Axthelm MK, Picker LJ: Development and homeostasis of T cell memory in rhesus macaque. J Immunol 2002, 168:29-43

67. Hosseini I, Gama L, Mac Gabhann F: Multiplexed component analysis to identify genes contributing to the immune response during acute SIV infection. PLoS One 2015, 10:e0126843

68. Chakrabarti L, Isola P, Cumont M-C, Claessens-Maire M-A, Hurtrel M, Montagnier L, Hurtrel B: Early stages of simian immunodeficiency virus infection in lymph nodes: evidence for high viral load and successive populations of target cells. Am J Pathol 1994, $144: 1226$

69. Kumar A, Abbas W, Herbein G: HIV-1 latency in monocytes/macrophages. Viruses 2014, 6:1837-1860

70. Le Douce V, Herbein G, Rohr O, Schwartz C: Molecular mechanisms of HIV-1 persistence in the monocyte-macrophage lineage. Retrovirology 2010, 7:32

71. Buechler C, Ritter M, Orso E, Langmann T, Klucken J, Schmitz G: Regulation of scavenger receptor CD163 expression in human monocytes and macrophages by pro-and antiinflammatory stimuli. J Leukoc Biol 2000, 67:97

72. Goebeler M, Roth J, Teigelkamp S, Sorg C: The monoclonal antibody MAC387 detects an epitope on the calcium-binding protein MRP14. J Leukoc Biol 1994, 55:259-261

73. Yona S, Kim K-W, Wolf Y, Mildner A, Varol D, Breker M, StraussAyali D, Viukov S, Guilliams M, Misharin A: Fate mapping reveals origins and dynamics of monocytes and tissue macrophages under homeostasis. Immunity 2013, 38:79-91

74. Ito S, Ansari P, Sakatsume M, Dickensheets H, Vazquez N, Donnelly RP, Larner AC, Finbloom DS: Interleukin-10inhibits expression of both interferon a- and interferon $\gamma$ - induced genes by suppressing tyrosine phosphorylation of STAT1. Blood 1999, 93: $1456-1463$

75. Wang X-F, Wang H-S, Wang H, Zhang F, Wang K-F, Guo Q, Zhang G, Cai S-H, Du J: The role of indoleamine 2,3-dioxygenase (IDO) in immune tolerance: focus on macrophage polarization of THP-1 cells. Cell Immunol 2014, 289:42-48

76. Martinez FO, Gordon S: The M1 and M2 paradigm of macrophage activation: time for reassessment. F1000Prime Rep 2014, 6:13

77. van der Lans AA, Boon MR, Haks MC, Quinten E, Schaart G, Ottenhoff TH, van Marken Lichtenbelt WD: Cold acclimation affects 
immune composition in skeletal muscle of healthy lean subjects. Physiol Rep 2015, 3:e12394

78. Brown BN, Ratner BD, Goodman SB, Amar S, Badylak SF: Macrophage polarization: an opportunity for improved outcomes in biomaterials and regenerative medicine. Biomaterials 2012, 33: 3792-3802

79. Buckner CM, Calderon TM, Eugenin EA, Carvallo L, Williams D, Lopez L, Belbin T, Berman JW: Characterization of stages of monocyte maturation/differentiation that facilitate their transmigration across the blood brain barrier and infection by HIV: implications for NeuroAIDS. Cell Immunol 2011, 267:109-123

80. Williams DW, Calderon TM, Lopez L, Carvallo-Torres L, Gaskill PJ, Eugenin EA, Morgello S, Berman JW: Mechanisms of HIV entry into the CNS: increased sensitivity of HIV infected CD14+CD16+ monocytes to CCL2 and key roles of CCR2, JAM-A, and ALCAM in diapedesis. PLoS One 2013, 8:e69270

81. Wang X, Xu H, Alvarez X, Pahar B, Moroney-Rasmussen T, Lackner AA, Veazey RS: Distinct expression patterns of CD69 in mucosal and systemic lymphoid tissues in primary SIV infection of rhesus macaques. PLoS One 2011, 6:e27207

82. Otani I, Mori K, Sata T, Terao K, Doi K, Akari H, Yoshikawa Y: Accumulation of MAC387+ macrophages in paracortical areas of lymph nodes in rhesus monkeys acutely infected with simian immunodeficiency virus. Microbes Infect 1999, 1:977-985

83. Lakritz JR, Bodair A, Shah N, O’Donnell R, Polydefkis MJ, Miller AD, Burdo TH: Monocyte traffic, dorsal root ganglion histopathology, and loss of intraepidermal nerve fiber density in SIV peripheral neuropathy. Am J Pathol 2015, 185:1912-1923

84. Fischer-Smith T, Tedaldi EM, Rappaport J: CD163/CD16 coexpression by circulating monocytes/macrophages in HIV: potential biomarkers for HIV infection and AIDS progression. AIDS Res Hum Retroviruses 2008, 24:417-421

85. Williams DW, Eugenin EA, Calderon TM, Berman JW: Monocyte maturation, HIV susceptibility, and transmigration across the blood brain barrier are critical in HIV neuropathogenesis. J Leukoc Biol 2012, 91:401-415

86. Pretlow T, Pretlow T: Analysis and separation of stromal cells infiltrating tumors. Cell Separat Methods Selected Appl 2014, 2:63

87. Pochedly CE: Disorders of the Spleen: Pathophysiology and Management. Abingdon, UK: Taylor \& Francis, 1989

88. Connick E, Folkvord JM, Lind KT, Rakasz EG, Miles B, Wilson NA, Santiago ML, Schmitt K, Stephens EB, Kim HO: Compartmentalization of simian immunodeficiency virus replication within secondary lymphoid tissues of rhesus macaques is linked to disease stage and inversely related to localization of virus-specific CTL. J Immunol 2014, 193:5613-5625
89. Rainho JN, Martins MA, Cunyat F, Watkins IT, Watkins DI, Stevenson M: Nef is dispensable for resistance of SIV-infected macrophages to CD8 $+\mathrm{T}$ cell killing. J Virol 2015, 89: 10625-10636

90. D'Andrea A, Aste-Amezaga M, Valiante NM, Ma X, Kubin M, Trinchieri G: Interleukin 10 (IL-10) inhibits human lymphocyte interferon gamma-production by suppressing natural killer cell stimulatory factor/IL-12 synthesis in accessory cells. J Exp Med 1993, 178:1041-1048

91. Zaritsky LA, Dery A, Leong WY, Gama L, Clements JE: Tissuespecific interferon alpha subtype response to SIV infection in brain, spleen, and lung. J Interferon Cytokine Res 2013, 33:24-33

92. Qin H, Holdbrooks AT, Liu Y, Reynolds SL, Yanagisawa LL, Benveniste EN: SOCS3 deficiency promotes M1 macrophage polarization and inflammation. J Immunol 2012, 189:3439-3448

93. Mulder R, Banete A, Basta S: Spleen-derived macrophages are readily polarized into classically activated (M1) or alternatively activated (M2) states. Immunobiology 2014, 219:737-745

94. Tuluc F, Meshki J, Spitsin S, Douglas SD: HIV infection of macrophages is enhanced in the presence of increased expression of CD163 induced by substance P. J Leukoc Biol 2014, 96:143-150

95. Yearley JH, Pearson C, Shannon RP, Mansfield KG: Phenotypic variation in myocardial macrophage populations suggests a role for macrophage activation in SIV-associated cardiac disease. AIDS Res Hum Retroviruses 2007, 23:515-524

96. Nowlin BT, Burdo TH, Midkiff CC, Salemi M, Alvarez X, Williams KC: SIV encephalitis lesions are composed of CD163+ macrophages present in the central nervous system during early SIV infection and SIV-positive macrophages recruited terminally with AIDS. Am J Pathol 2015, 185:1649-1665

97. Cassol E, Cassetta L, Rizzi C, Alfano M, Poli G: M1 and M2a polarization of human monocyte-derived macrophages inhibits HIV-1 replication by distinct mechanisms. J Immunol 2009, 182: $6237-6246$

98. Herbein G, Varin A: The macrophage in HIV-1 infection: from activation to deactivation. Retrovirology 2010, 7:1-15

99. Swirski FK, Nahrendorf M, Etzrodt M, Wildgruber M, CortezRetamozo V, Panizzi P, Figueiredo J-L, Kohler RH, Chudnovskiy A, Waterman P, Aikawa E, Mempel TR, Libby P, Weissleder R, Pittet MJ: Identification of splenic reservoir monocytes and their deployment to inflammatory sites. Science 2009, 325:612-616

100. van der Laan AM, ter Horst EN, Delewi R, Begieneman MPV, Krijnen PAJ, Hirsch A, Lavaei M, Nahrendorf M, Horrevoets AJ, Niessen HWM, Piek JJ: Monocyte subset accumulation in the human heart following acute myocardial infarction and the role of the spleen as monocyte reservoir. Eur Heart J 2014, 35:376-385 